\title{
Clinical Practice Guideline for the Evaluation of Fever and Infection in Older Adult Residents of Long-Term Care Facilities: 2008 Update by the Infectious Diseases Society of America
}

\author{
Kevin P. High, MD, MS, Suzanne F. Bradley, MD, ${ }^{\text {bcd }}$ Stefan Gravenstein, MD, ${ }^{\text {efgh }}$ David R. Mehr, MD, ${ }^{i}$ \\ Vincent J. Quagliarello, MD, ${ }^{j}$ Chesley Richards, $M D,{ }^{k l}$ and Thomas T. Yoshikawa, $M D^{m n}$
}

Residents of long-term care facilities (LTCFs) are at great risk for infection. Most residents are older and have multiple comorbidities that complicate recognition of infection; for example, typically defined fever is absent in more than one-half of LTCF residents with serious infection. Furthermore, LTCFs often do not have the on-site equipment or personnel to evaluate suspected infection in the fashion typically performed in acute care hospitals. In recognition of the differences between LTCFs and hospitals with regard to hosts and resources present, the Infectious Diseases Society of America first provided guidelines for evaluation of fever and infection in LTCF residents in 2000. The guideline presented here represents the second edition, updated by data generated over the intervening 8 years. It focuses on

\footnotetext{
${ }^{a}$ Section on Infectious Diseases, Wake Forest University Health Sciences, Winston Salem, North Carolina; ${ }^{b}$ Divisions of Infectious Diseases and 'Geriatrics, Geriatric Research Education and Clinical Center (GRECC), Veterans Affairs Ann Arbor Healthcare System; ${ }^{\mathrm{d} U n i v e r s i t y ~ o f ~ M i c h i g a n ~}$ School of Medicine, Ann Arbor, Michigan; ${ }^{\mathrm{e}}$ AMDA Foundation Research Network; ${ }^{\mathrm{f}} \mathrm{Quality}$ Partners of Rhode Island; ${ }^{\mathrm{g}}$ Division of Geriatrics; ${ }^{\mathrm{h}}$ Department of Medicine, Alpert Medical School of Brown University, Providence, Rhode Island; ${ }^{\mathrm{i} C u r t i s} \mathrm{~W}$, and Ann H Long Department of Family and Community Medicine, University of Missouri School of Medicine, Columbia, Missouri; 'Section of Infectious Diseases, Yale University School of Medicine, New Haven, Connecticut; ${ }^{k}$ Division of Healthcare Quality Promotion, Centers for Disease Control and Prevention; ${ }^{\mathrm{l} D i v i s i o n}$ of Geriatric Medicine and Gerontology, Emory University School of Medicine, Atlanta, Georgia; ${ }^{\mathrm{m}}$ GRECC, Veterans Affairs Greater Los Angeles Healthcare System; and ${ }^{n}$ David Geffen School of Medicine, University of CaliforniaLos Angeles, Los Angeles, California.

It is important to realize that guidelines cannot always account for individual variation among patients. They are not intended to supplant physician judgment with respect to particular patients or special clinical situations. The Infectious Diseases Society of America considers adherence to these guidelines to be voluntary, with the ultimate determination regarding their application to be made by the physician in the light of each patient's individual circumstances.

*Reprinted from Clinical Infectious Diseases 2009;48:149-171 with permission from Infectious Diseases Society of America and University of Chicago Press.
}

Address correspondence to Dr. Kevin P. High, Sections on Infectious Diseases, Hematology/Oncology, and Molecular Medicine, Wake Forest University Health Sciences, 100 Medical Center Blvd., Winston Salem, NC 27157-1042. E-mail: khigh@wfubmc.edu.

DOI: 10.1111/j.1532-5415.2009.02175.x the typical elderly person institutionalized with multiple chronic comorbidities and functional disabilities (e.g., a nursing home resident). Specific topic reviews and recommendations are provided with regard to what resources are typically available to evaluate suspected infection, what symptoms and signs suggest infection in a resident of an LTCF, who should initially evaluate the resident with suspected infection, what clinical evaluation should be performed, how LTCF staff can effectively communicate about possible infection with clinicians, and what laboratory tests should be ordered. Finally, a general outline of how a suspected outbreak of a specific infectious disease should be investigated in an LTCF is provided. J Am Geriatr Soc 57:375-394, 2009.

\section{EXECUTIVE SUMMARY}

B $y$ the year 2030, $20 \%$ of the United States population is estimated to be aged $\geq 65$ years, and almost 30 million of these persons are anticipated to have functional limitations that will increase the need for long-term care. Currently, there are $>16,000$ nursing homes/facilities for long-term care in the United States in which $\sim 1.5$ million older adults reside. Care providers in long-term care facilities (LTCFs) are primarily nursing staff, and most contract with group practices or use private physicians from the local community for clinical services. Select specialty services and diagnostic tests are most often provided through contracts with outside providers (e.g., dental care, podiatry, and imaging). Other more-complex or technical services require the resident be transferred to an acute care facility.

Urinary tract infection (UTI), pneumonia, soft-tissue infection, gastroenteritis, and prosthetic device-associated infections are well-recognized problems among elderly LTCF residents and are very common. For example, UTI occurs at an incidence of 0.1-2.4 cases per 1,000 residentdays, and pneumonia develops among elderly nursing home 
residents at a rate of 1 episode per 1,000 days of care, which is 10 -fold greater than the rate of pneumonia among elderly persons who reside in the community. The common use of antibiotic therapy in LTCF residents for illness that is caused (or suspected to have been caused) by infection contributes to the high rates of antibiotic-resistant pathogens (e.g., methicillin-resistant Staphylococcus aureus and vancomycin-resistant Enterococcus species) and antibioticrelated complications, such as Clostridium difficile colitis, in this setting.

The multifaceted nature of the evaluation of patients in LTCFs has led to participation, review, and support of these recommendations by the following organizations: Infectious Diseases Society of America, Society for Healthcare Epidemiology of America and the American Geriatrics Society.

Additional and new information provided in this report since its first publication in 2000 include the importance of functional assessment as part of the infectious disease evaluation in an older adult; proper method of collecting urine samples from individuals with a long-term indwelling bladder catheter for purposes of microbiological evaluation, as well as use of the dipstick method for diagnosis of a UTI; use of pulse oximetry for pneumonia diagnosis in nursing home residents; diagnostic aspects of legionellosis respiratory infection; diagnostic information on respiratory syncytial virus infection in this setting; diagnosis of conjunctivitis and fungal skin infections in LTCF residents; and expansion of the section on gastrointestinal (GI) infections, including those due to norovirus, protozoas, C. difficile, and intraabdominal abscesses. These guidelines are specifically intended to apply to older adult residents of LTCFs. The potential heterogeneity of conditions present in LTCF residents (e.g., persons with spinal cord injuries or acute brain injury and young adults with rehabilitation needs) suggests that the recommendations described herein may not apply to all LTCF residents or to all such facilities, and thus, the recommendations are intended to assist with the management of the majority of LTCF residents (i.e., older adults with multiple comorbidities and functional disabilities).

\section{Resources}

Most LTCFs have limited diagnostic equipment on site and are staffed by nursing personnel (primarily certified nurse assistants [CNAs]). Specific data are available to make recommendations for personnel, but no data are available to guide minimal requirements for diagnostic equipment.

1. LTCFs should employ sufficient staff to adequately care for all residents (B-III).

\section{Symptoms and Signs of Suspected Infection}

Typical symptoms and signs of infection are frequently absent in LTCF residents, and as one ages and becomes more frail, basal body temperature decreases, making it less likely that one will achieve classic definitions of fever. Infection should be suspected in residents with the following characteristics:

2. Infection should be suspected in LTCF residents with:

A. Decline in functional status, defined as new or increasing confusion, incontinence, falling, deteriorating mobility, reduced food intake, or failure to cooperate with staff (B-II).

B. Fever, defined as: (1) A single oral temperature $>100^{\circ} \mathrm{F}$ $\left(>37.8^{\circ} \mathrm{C}\right)$; or $(2)$ repeated oral temperatures $>99^{\circ} \mathrm{F}$ $\left(>37.2^{\circ} \mathrm{C}\right)$ or rectal temperatures $>99.5^{\circ} \mathrm{F}\left(>37.5^{\circ} \mathrm{C}\right)$; or (3) an increase in temperature of $>2^{\circ} \mathrm{F}\left(>1.1^{\circ} \mathrm{C}\right)$ over the baseline temperature (B-III).

\section{Evaluation of the Resident}

CNAs are almost always the first to recognize a symptom or sign of infection in LTCF residents, but data suggest that they frequently misinterpret these clinical clues.

3. The initial clinical evaluation of infection should be a 3- tiered approach involving a CNA, the on-site nurse, and an advanced-practice nurse, physician assistant, or physician (B-III).

4. CNAs should measure vital signs (temperature, heart rate, blood pressure, and respiratory rate). Residents who are suspected of having an infection or who have fever, as defined previously, should be reported immediately to the on-site nurse (B-II).

\section{Clinical Evaluation}

Few data are available to suggest which of the most helpful clinical evaluations should be performed in LTCF residents with suspected infection. However, on the basis of the most common sites of infection and the tenuous physiologic reserve for most residents of LTCFs, the following recommendations can be made:

5. Initial clinical evaluation should involve assessment of respiratory rate, hydration status, mental status, oropharynx, conjunctiva, skin (including sacral, perineum, and perirectal areas), chest, heart, abdomen, and indwelling devices (if present) (B-III).

\section{Communication}

Effective communication of a resident's status is perhaps intuitive, but some guiding principles can be stated.

6. Information should be relayed to the responsible advancepractice nurse, physician assistant, or physician for decisions regarding further evaluation (B-III).

7. The full extent of the clinical evaluation should be documented as part of the medical record. If specific diagnostic measures are consciously withheld, the reasons should be recorded (B-III).

\section{Laboratory Tests}

A full summary of the evaluations for laboratory tests in specific situations is not possible, because they are too numerous to list. The reader is referred to the recommendations for specific syndromes (i.e., UTI, pneumonia, GI infection, and skin and soft-tissue infection [SSTI]). However, several overall guiding principles can be highlighted. 


\section{Initial Diagnostic Testing}

8. Advance directives for residents should be reviewed prior to any intervention; if not prohibited by such directives, initial diagnostic tests for suspected infection can be performed in the LTCF if resources are available and if studies can be done in a timely manner (B-III).

\section{Blood Cell Count}

9. A complete blood cell (CBC) count, including peripheral white blood cell (WBC) and differential cell counts (preferably a manual differential to assess bands and other immature forms), should be performed for all LTCF residents who are suspected of having infection within 12-24 h of onset of symptoms (or sooner, if the resident is seriously ill), consistent with local standards of practice (B-II).

10. The presence of an elevated WBC count (WBC count, $\geq 14,000$ cells $/ \mathrm{mm}^{3}$ ) or a left shift (percentage of band neutrophils or metamyelocytes, $>6 \%$; or total band neutrophil count, $\geq 1,500$ cells $/ \mathrm{mm}^{3}$ ) warrants a careful assessment for bacterial infection in any LTCF resident with suspected infection, with or without fever (B-II).

11. In the absence of fever, leukocytosis and/or left shift, or specific clinical manifestations of a focal infection, additional diagnostic tests may not be indicated, because of the low potential yield (C-III). Nonbacterial infections, however, cannot be excluded.

\section{Urinalysis and Urine Culture}

12. Urinalysis and urine cultures should not be performed for asymptomatic residents (A-I).

13. In noncatheterized residents, the diagnostic laboratory evaluation of suspected UTI should be reserved for those with acute onset of UTI-associated symptoms and signs (e.g., fever, dysuria, gross hematuria, new or worsening urinary incontinence, and/or suspected bacteremia) (A-II).

14. In residents with long-term indwelling urethral catheters, evaluation is indicated if there is suspected urosepsis (i.e., fever, shaking chills, hypotension, or delirium), especially in the context of recent catheter obstruction or change (A-II).

15. Appropriately collected urine specimens include a midstream or clean-catch specimen obtained from elderly men who are cooperative and functionally capable; however, it is often necessary to use a freshly applied, clean condom external collection system, with frequent monitoring of the urine bag (B-II). Specimen collection from women will often require an in-and-out catheterization (B-III).

16. Residents with long-term indwelling urethral catheters and suspected urosepsis should have catheters changed prior to specimen collection and institution of antibiotic therapy (A-II).

17. The minimum laboratory evaluation for suspected UTI should include urinalysis for determination of leukocyte esterase and nitrite level by use of a dipstick and a microscopic examination for WBCs (B-II). If pyuria
( $>10 \mathrm{WBCs} /$ high-power field) or a positive leukocyte esterase or nitrite test is present on dipstick, only then should a urine culture (with antimicrobial susceptibility testing) be ordered (B-III).

18. If urosepsis is suspected, urine and paired blood specimens should be obtained, if feasible, for culture and antimicrobial susceptibility testing, and a Gram stain of uncentrifuged urine should be requested (B-III).

\section{Blood Culture}

19. In a study of older adult nursing home residents, blood cultures were demonstrated to have a low yield and rarely to influence therapy; thus, they are not recommended for most residents of LTCFs (B-II) (note: this may not apply to all types of residents or to all types of LTCFs). Blood cultures may be appropriate for residents in whom bacteremia is highly suspected and if the LTCF has quick access to laboratory facilities, adequate physician coverage to respond to positive culture results, and a capacity to administer parenteral antibiotics.

\section{Pneumonia Evaluation}

If pneumonia is clinically suspected and resources are available, the following diagnostic studies should be performed:

20. Pulse oximetry should be performed for residents with respiratory rates of $>25$ breaths $/ \mathrm{min}$, to document hypoxemia (oxygen saturation, $<90 \%$ ) in residents with suspected pneumonia and to guide transfer to an acute care facility pending the resident's or family's wishes (B-II).

21. Chest radiography should be performed if hypoxemia is documented or suspected, to identify the presence of a new infiltrate compatible with acute pneumonia and to exclude other complicating conditions (e.g., multilobe infiltrates, large pleural effusions, congestive heart failure, or mass lesions) (B-II).

\section{Respiratory Viral Infection Evaluation}

22. At the onset of a suspected respiratory viral infection outbreak, nasopharyngeal wash or swab samples obtained from the throat and nasopharynx (combined with refrigerated viral transport media in a single tube) should be obtained from several acutely ill residents for transportation to an experienced laboratory for virus isolation and rapid diagnostic testing for influenza $\mathrm{A}$ virus and other common viruses (A-III).

\section{Evaluation of Skin and Soft Tissue Infection (SSTI)}

23. Bacterial cultures should be performed only under select conditions. Surface swab cultures are not indicated for the diagnosis of most bacterial SSTIs (A-II), with the exception of conjunctivitis (B-III). Needle aspiration (only skilled physicians should perform this procedure) or deep-tissue biopsy to obtain samples for Gram stain and culture may be appropriate in special circumstances in which unusual pathogens are suspected, fluctuant areas suggest an abscess is present, or 
initial antimicrobial treatment has been unsuccessful (C-III).

24. If a pressure ulcer demonstrates poor healing and/or persistent purulent drainage, obtain deep specimens for culture of tissue and bone specimens at the time of surgical debridement or biopsy (B-II). Magnetic resonance imaging (MRI) is the most sensitive imaging modality to detect osteomyelitis, but bone biopsy for histopathologic examination definitively confirms the diagnosis and is most useful in guiding antimicrobial therapy (A-III).

25. For suspected mucocutaneous fungal infection, a scraping can be performed for potassium hydroxide $10 \%$ preparation to verify the presence of yeast or dermatophytes (B-III). If mucocutaneous candidiasis is refractory to empirical treatment, culture can be performed for the detection of drug-resistant species (B-III).

26. For suspected herpes simplex or herpes zoster, skin scrapings may be examined for the presence of giant cells (Tzanck preparation) and/or sent for culture, immunofluorescent viral antigen studies, or polymerase chain reaction (PCR) (A-III).

27. Scabies should be considered in any nursing home resident with a generalized rash that is unexplained. Diagnosis should be attempted by light microscopy demonstration of mites, eggs, or mite feces on mineral oil preparations of several scrapings (B-III). If proper diagnostic equipment is not available and if clinical experience with scabies is limited, consider consultation with a dermatologist to inspect or obtain scrapings from suspected persons (C-III).

\section{Evaluation of GI Infection}

28. In the absence of an outbreak of GI illness, residents with symptoms of gastroenteritis consistent with small bowel infection and a stable clinical status should be evaluated before 7 days for volume assessment, but no laboratory evaluation is required unless the resident is severely ill or symptoms persist beyond 7 days. In such cases, presence of Giardia species and other protozoa should be examined in stool specimens (B-III).

29. If the resident exhibits symptoms of colitis (e.g., severe fever, abdominal cramps, and/or diarrhea, with or without blood and/or WBCs in the stool), initial evaluation for C. difficile should be performed, especially if the patient has received antibiotics within the previous 30 days. Submit a single diarrheal stool specimen to the laboratory for a $C$. difficile toxin assay. If diarrhea persists and if the assay result is negative, submit 1 or 2 additional stool specimens for the toxin assay (A-II).

30. In a patient with symptoms of colitis but no history of antibiotic use within the previous 30 days and/or a negative C. difficile evaluation result, one should submit a stool sample for culture for isolation of the most frequent invasive enteropathogens (i.e., Campylobacter jejuni, Salmonella and Shigella species, and Escherichia coli O157:H7) (A-II).

31. Local public health authorities should be consulted if rates of gastroenteritis or colitis exceed baseline thresholds in the facility (if these thresholds are known), if $\geq 2$ cases occur at the same time in the same unit, or if a reportable pathogen is isolated (B-III).

32. Intra-abdominal infections and abscesses can occur in LTCF residents as a consequence of GI pathology. These complications are relatively uncommon but are associated with substantial morbidity and mortality; evaluation and treatment of possible abscesses should be performed in an acute care setting (B-III).

\section{Suspected Outbreak}

A broad description of an outbreak investigation is beyond the scope of these guidelines, but a general guide is provided, including circumstances in which appropriate authorities (e.g., the Centers for Disease Control and Prevention) should be notified. An important aspect of the outbreak investigation is that residents with advanced directives that prohibit testing can and often should be tested if the goal is not for care of that specific patient but reduction in the risk of illness in others.

33. During a possible outbreak of infection, testing of residents, regardless of advanced directive status, may be warranted for diagnostic and infection-control purposes for the protection of other residents and staff (B-III).

\section{PRACTICE GUIDELINES AND UPDATE METHODOLOGY}

\section{Practice Guidelines}

Practice guidelines are systematically developed statements to assist practitioners and patients in making decisions about appropriate health care for specific clinical circumstances. ${ }^{1}$ Attributes of good guidelines include validity, reliability, reproducibility, clinical applicability, clinical flexibility, clarity, multidisciplinary process, review of evidence, and documentation. ${ }^{1}$

\section{Panel Composition}

The Infectious Diseases Society of America (IDSA) Standards and Practice Guidelines Committee (SPGC) convened experts in the evaluation of residents with fever and infection in LTCFs. The Panel's expertise included infectious diseases, geriatrics, primary care, long-term care, and epidemiology/infection control.

\section{Literature Review and Analysis}

For the 2008 update, the Expert Panel completed the review and analysis of data published since 1999. Computerized literature searches (with the PubMed database) of the English-language literature published from 1999 through 2007 were performed. Search terms included "long-term care," "geriatrics," "infection," "communication," "testing," "outbreaks," "fever," "nursing home infections," "sepsis," "bacteremia," "pneumonia," "urinary tract infection," "pressure ulcers," "gastrointestinal infections," "scabies," "herpes zoster," "clostridium difficile," "candida," "bacterial diarrhea," "giardiasis," "influenza," "conjunctivitis," and "advance directives." 
Table 1. Infectious Diseases Society of America-U.S. Public Health Service Grading System for Ranking Recommendations in Clinical Guidelines

\begin{tabular}{|c|c|}
\hline $\begin{array}{c}\text { Category, } \\
\text { Grade }\end{array}$ & Definition \\
\hline \multicolumn{2}{|c|}{ Strength of recommendation } \\
\hline A & Good evidence to support a recommendation for use \\
\hline B & Moderate evidence to support a recommendation for use \\
\hline C & Poor evidence to support a recommendation \\
\hline \multicolumn{2}{|c|}{ Quality of evidence } \\
\hline 1 & Evidence from $\geq 1$ properly randomized, controlled trial \\
\hline II & $\begin{array}{l}\text { Evidence from } \geq 1 \text { well-designed clinical trial, without } \\
\text { randomization; from cohort or case-controlled analytical } \\
\text { studies (preferably from }>1 \text { center); from multiple time- } \\
\text { series; or from dramatic results from uncontrolled experiments }\end{array}$ \\
\hline III & $\begin{array}{l}\text { Evidence from opinions of respected authorities, based on } \\
\text { clinical experience, descriptive studies, or reports of expert } \\
\text { committees }\end{array}$ \\
\hline
\end{tabular}

NOTE. Adapted from Canadian Task Force on the Periodic Health Examination. ${ }^{2}$

\section{Process Overview}

In assessing the evidence regarding the evaluation of fever and infection in LTCF residents, the Expert Panel followed a process used in the development of other IDSA guidelines. The process included a systematic weighting of the quality of the evidence and the grade of recommendation (Table 1). ${ }^{2}$

\section{Consensus Development Based on Evidence}

The Expert Panel met on four occasions via teleconference to complete the work of the guidelines. The purpose of the teleconferences was to discuss the questions to be addressed, to make writing assignments, and to discuss recommendations. All members of the Expert Panel participated in the preparation and review of the draft guidelines. Feedback from external peer reviews was obtained. The guidelines were reviewed and approved by the SPGC and the Board of Directors prior to dissemination.

\section{Guidelines and Conflicts of Interest}

All members of the Expert Panel complied with the IDSA policy on conflicts of interest, which requires disclosure of any financial or other interest that might be construed as constituting an actual, potential, or apparent conflict. Members of the Expert Panel were provided the IDSA's conflict of interest disclosure statement and were asked to identify associations with companies developing products that may be affected by promulgation of the guidelines. Information was requested regarding employment, consultancies, stock ownership, honoraria, research funding, expert testimony, and membership on company advisory committees. The Expert Panel made decisions on a case-bycase basis as to whether an individual's role should be limited as a result of a conflict. Potential conflicts are listed in the Acknowledgments section.

\section{Revision Dates}

At annual intervals, the Panel Chair, the SPGC liaison advisor, and the Chair of the SPGC will determine the need for revisions to the guideline on the basis of an examination of current literature. If necessary, the entire Expert Panel will be reconvened to discuss potential changes. If appropriate, the Expert Panel will recommend revision of the guidelines to the SPGC and the IDSA Board for review and approval.

\section{INTRODUCTION}

In 2000, the IDSA published clinical practice guidelines on the evaluation of fever and infection in LTCFs. ${ }^{3}$ The IDSA updates its guidelines when new data or publications might change a prior recommendation or when the Expert Panel feels clarifications or additional guidance is warranted.

The previous document is a source for a more detailed review of earlier studies, ${ }^{3}$ and the reader is referred to that document for additional information. The Expert Panel addressed the following questions in the 2008 Update.

1. What are the minimum resources required to evaluate suspected infection in LTCFs?

2. What are the criteria for fever and symptoms and signs that suggest infection in a resident of an LTCF?

3. Who should perform the initial evaluation of the resident with suspected infection?

4. What clinical evaluation should be performed for an LTCF resident with suspected infection?

5. How can LTCF staff effectively communicate concerns about possible infection with clinicians who will be making treatment decisions?

6. What laboratory tests should be ordered for the LTCF resident with suspected infection?

7. How should a suspected outbreak of a specific infectious disease be investigated in LTCFs?

\section{BACKGROUND}

\section{Public Health Importance: Demographic Characteristics of the Aging Population and Long-Term Care}

The aged human population is undergoing unprecedented growth in the United States and globally. Multiple nations have $>2$ million older citizens each, and the number is expected to grow within the next few decades, with the greatest burden in the developing world., ${ }^{4,5}$ By the year 2030 , it is estimated that $20 \%$ of the U.S. population will be aged $\geq 65$ years, among whom almost 30 million persons are anticipated to have functional limitations within the ensuing decade. ${ }^{6,7}$ These estimates are linked to the rising need for long-term care, particularly in nursing homes/facilities, in the United States.

Currently, in the United States, there are $>16,000$ nursing homes/facilities for long-term care in which $\sim 1.5$ million older adults reside. More than $90 \%$ of these facilities are either proprietary or voluntary nonprofit, with the majority housing 50-200 residents each. Care providers within facilities are primarily nursing staff, with an average of 7 registered nurses (RNs), 13 licensed practical nurses (LPNs), and 35 CNAs per 100 resident beds. ${ }^{8}$ The minority $(19.6 \%)$ have physician providers on fulltime staff. The majority have contracts with group practices or use private physicians from the local community. Select specialty services and diagnostic testing are most often provided 
through contracts with outside providers (e.g., dental care, podiatry, and imaging services). ${ }^{8}$ Other more complex or technical services require hospitalization of the resident. Overall, care needs are becoming increasingly complex for this population, which consists primarily of elderly women (median age, $\sim 85$ years) who are afflicted with a variety of comorbid conditions (e.g., dementia, stroke, or congestive heart failure) and who have functional limitations in mobility and dependence in activities of daily living (e.g., bathing, dressing, and toileting). ${ }^{9}$

\section{Multifactorial Risks of Infection in Older Adults in LTCFs}

The convergence of age-associated impairments in immunity, increasing prevalence of comorbid disease, functional limitations of extreme age, and residence in group quarters within a nursing home/facility increase the risk burden for infectious disease. ${ }^{5,10,11}$ The specific nature of senescence of the immune system with normal aging has been an area of increasing investigation, with evidence supporting impairments in adaptive (e.g., B and $\mathrm{T}$ cell function) and innate immunity (e.g., surface expression or function of Toll-like receptors) that may relate to the increased risk of disease due to specific pathogens (e.g., Listeria species, Mycobacterium tuberculosis, and varicella-zoster virus) and an impaired response to vaccination (e.g., influenza, pneumococcus, and zoster vaccines). ${ }^{7,12-15}$ Concomitant comorbidities (e.g., diabetes mellitus, obstructive lung disease, urinary obstruction, impaired swallowing, poor dentition, and implanted prosthetic devices) further enhance the risk for common healthcare-associated infectious syndromes in the urinary tract, lung, and soft tissue. The common use of empirical antibiotic therapy for these conditions results in the additional complications of infections with antibioticresistant pathogens (e.g., methicillin-resistant S. aureus, vancomycin-resistant Enterococcus species, multidrug-resistant gram-negative bacilli) and C. difficile colitis. ${ }^{16}$ As a result, the LTCF has become a reservoir for antibioticresistant pathogens in which elderly residents requiring periodic hospitalization may carry resistant organisms across sites of care.

\section{Burden of Infection}

Although UTI, pneumonia, soft-tissue infection, gastroenteritis, and indwelling device-associated infections are well-recognized problems among elderly nursing home residents, UTI and pneumonia represent the greatest infectious disease burden. For example, UTI is the most commonly reported bacterial infection in nursing home residents, with an incidence of 0.1-2.4 cases per 1,000 resident-days, and it is a leading source of sepsis and death. ${ }^{17}$ Similarly, pneumonia develops among elderly nursing home residents at a rate of 1 episode per 1,000 days of care, which is 10 -fold greater than the rate of pneumonia among elderly community dwellers. At the current rate, by the year 2030, there will be almost 2 million episodes of nursing home-acquired pneumonia annually, with its inherent consequences of mortality, morbidity, functional decline, and healthcare expenditures. ${ }^{18-20}$
RECOMMENDATIONS FOR THE EVALUATION OF FEVER AND INFECTION IN LTCFs

\section{WHAT ARE THE MINIMUM RESOURCES REQUIRED TO EVALUATE SUSPECTED INFECTION IN LTCFs?}

Recommendation

1. LTCFs should employ sufficient staff to adequately care for all residents (B-III).

\section{Evidence Summary}

When clinicians evaluate suspected infection in hospitalized patients, diagnostic technologies are usually readily available, and there are a variety of staff trained in acutely evaluating changes in health status. In contrast, the overarching goals of care for LTCF residents are patient comfort, maintenance or improvement of functional status, stabilization of chronic illnesses, and prevention of new health problems, and care is most often provided by the nursing staff (primarily CNAs) under the direction of a director of nursing. LTCF resident-to-healthcare staff ratios are considerably lower than patient-to-staff ratios at acute care hospitals. Although there is no federal standard for specific levels of nurse staffing in a nursing home, the Centers for Medicare and Medicaid Services requires nursing homes to employ sufficient staff to adequately care for all residents. ${ }^{21}$ Staffing guidelines should be adjusted according to case mix and acuity of the residents. A threshold for acceptable ratios of nursing staff to residents can be recommended on the basis of this study, as follows: ratio of CNAs to residents, $\geq 1: 12$; ratio of RNs plus LPNs to residents, $\geq 1: 30$; and ratio of RNs to residents, $\geq 1: 120 .^{21}$

Relatively few physicians practice in an LTCF, and routine physician visits are infrequent - often monthly or even less frequent, depending on state or federal regulations. Some visits may be made by cross-covering physicians or physician extenders (i.e., physician assistants and advance-practice nurses). Between these visits, initiation of diagnostic testing and changes in medications and other treatments are usually accomplished by telephone communication..$^{22-24}$

Technologies available for the prompt diagnosis of infection in hospitals are often difficult to access in the LTCF. Vital signs generally are obtained on a weekly basis for stable residents who require long-term maintenance care; however, more frequent measurements can be obtained on the basis of nursing judgment or physician order. Criteria for infections that rely less on diagnostic studies and more on patient symptoms and signs and on resources that are more readily available in LTCFs have been developed and widely used but not validated. ${ }^{25,26}$

There is no minimum requirement that diagnostic equipment be present on-site for evaluation of fever and suspected infection in LTCFs other than for equipment used for clinical assessment. Immediately available laboratory tests and radiography equipment are sometimes located on-site, but personnel to operate these devices are almost never available every day, $24 \mathrm{~h}$ per day. Contract organizations often provide services, and subspecialty or surgical consultation is very rarely available except for LTCFs attached to acute care hospitals. Cost and capitated care may influence decisions to transport patients off site for diagnostic evaluation. 


\section{WHAT ARE THE CRITERIA FOR FEVER AND SYMPTOMS AND SIGNS THAT SUGGEST INFECTION IN A RESIDENT OF AN LTCF?}

\section{Recommendation}

2. Infection should be suspected in LTCF residents with:

A. Decline in functional status, defined as new or increasing confusion, incontinence, falling, deteriorating mobility, reduced food intake, or failure to cooperate with staff (B-II).

B. Fever, defined as: (1) A single oral temperature $>100^{\circ} \mathrm{F}$ $\left(>37.8^{\circ} \mathrm{C}\right)$; or $(2)$ repeated oral temperatures $>99^{\circ} \mathrm{F}$ $\left(>37.2^{\circ} \mathrm{C}\right)$ or rectal temperatures $>99.5^{\circ} \mathrm{F}\left(>37.5^{\circ} \mathrm{C}\right)$; or (3) an increase in temperature of $>2^{\circ} \mathrm{F}\left(>1.1^{\circ} \mathrm{C}\right)$ over the baseline temperature (B-III).

\section{Evidence Summary}

\section{Clinical Manifestations of Infection}

As in younger adults, the clinical clues that an infection might be present in an older person include fever and some obvious clinical signs (e.g., erythema and purulence of the eye [conjunctivitis]; heat, redness, purulence, and skin breakdown [infected pressure ulcer]; and cough and yellow sputum [respiratory infection]). However, clinical findings in infected elderly residents in LTCFs may also be absent or too subtle to be recognized by the staff, or infection may manifest atypically as a change in mental or cognitive function or a decline in physical functional status (e.g., the person is unable to perform the usual activities of daily living). Berman et al. ${ }^{27}$ determined that infection is present in $77 \%$ of episodes of "decline in function," defined as new or increasing confusion, incontinence, falling, deteriorating mobility, or failure to cooperate with rehabilitation. Ascertaining the functional status or functional capacity of older persons with infection before, during, and after resolution of infection is an essential aspect of managing the health care in the geriatric population. ${ }^{5}$

Thus, LTCF residents may have typical or atypical presentations of infection. ${ }^{27-30}$ For example, Brooks et al. ${ }^{31}$ found "typical" symptoms and signs of UTI, such as fever $(30 \%$; absolute temperature criterion for fever was not defined), were not sensitive indicators of infection in LTCF residents. In contrast, persons with respiratory tract infection (RTI) more often presented with classic manifestations (cough, $75 \%$; fever, $62 \%$; and rales, $55 \%$ ). In another large study, just $44 \%$ of nursing home residents with possible or probable pneumonia noted on a chest radiograph had a temperature of $\geq 38^{\circ} \mathrm{C}$, but only $7.5 \%$ had no respiratory symptoms. ${ }^{32}$

\section{Fever Criteria in Residents of LTCFs}

There are several methods to determine whether fever is present in the LTCF resident. Basal body temperatures in frail, elderly persons may be lower than the well-established mean value of $37^{\circ} \mathrm{C}$ or $98.6^{\circ} \mathrm{F}^{33} \mathrm{In}$ a study by Castle et al. ${ }^{34}$ in which all temperatures were determined orally or rectally with use of an electronic thermistor probe and in which subjects were mostly male veteran nursing-facility residents, a single temperature reading of $101^{\circ} \mathrm{F}\left(38.3^{\circ} \mathrm{C}\right)$ had a sensitivity of only $40 \%$ for predicting infection. Lowering the criterion to $100^{\circ} \mathrm{F}\left(37.8^{\circ} \mathrm{C}\right)$ raised the sensitivity to $70 \%$ for predicting infection while maintaining excellent speci- ficity at $90 \%$. Thus, according to Castle et al., ${ }^{34}$ a single temperature reading of $\geq 100^{\circ} \mathrm{F}\left(37.8^{\circ} \mathrm{C}\right)$ is both a sensitive and specific predictor of infection, with a positive predictive value of $55 \%$, in LTCF residents. Other suggested temperature criteria indicative of possible infection in LTCF residents are an increase in temperature of at least $2^{\circ} \mathrm{F}\left(1.1^{\circ} \mathrm{C}\right)$ over baseline or an oral temperature of $\geq 99^{\circ} \mathrm{F}\left(37.2^{\circ} \mathrm{C}\right)$ or a rectal temperature of $\geq 99.5^{\circ} \mathrm{F}\left(37.5^{\circ} \mathrm{C}\right)$ on repeated measurements. ${ }^{34,35}$

Although temperatures in LTCF residents are most often measured in the mouth, there is some evidence that rectal measurements of temperatures may be more accurate than either the oral or axillary method and that electronic techniques are better than standard mercury thermometry. ${ }^{36,37}$ Another alternative method for measuring temperature is tympanic membrane thermometry. In one study of nursing home residents, the correlation of tympanic membrane thermometry versus rectal thermometry was somewhat better than oral versus rectal thermometry. ${ }^{38}$ However, there are insufficient data to recommend the tympanic membrane method for measuring fever in older persons.

\section{WHO SHOULD PERFORM THE INITIAL EVALUATION OF THE RESIDENT WITH SUSPECTED INFECTION?}

\section{Recommendations}

3. The initial clinical evaluation of infection should be a three-tiered approach involving a CNA, the on-site nurse, and an advanced-practice nurse, physician assistant, or physician (B-III).

4. CNAs should measure vital signs (temperature, heart rate, blood pressure, and respiratory rate). Residents who are suspected of having an infection or who have fever, as defined previously, should be reported immediately to the on-site nurse (B-II).

\section{Evidence Summary}

Once infection is suspected or fever is established by the criteria outlined above, clinical evaluation of LTCF residents with suspected infection (i.e., clinical manifestations of infection or decline in functional status) should be a three-tiered level of evaluation that includes CNAs, the onsite nurse (charge nurse), and the responsible physician or physician extender (i.e., advanced- practice nurses or physician assistant). A number of studies have reported use of advanced-practice nurses (e.g., nurse practitioners) to assess acute problems in residents of LTCFs as an approach to improve evaluation. ${ }^{23,39-41}$ Evidence suggests that geriatric nurse practitioners (GNPs) can enhance identification of acute medical problems (including fever) and improve activities of daily living, nursing therapies, and drug treatments, compared with the absence of GNPs. ${ }^{40}$ However, GNPs do not alter overall outcomes, as measured by the resident's functional status, physical condition, and satisfaction. ${ }^{42}$ Specific outcome data do not exist for infection. It is unknown whether NPs without geriatric certification will perform equally well.

CNAs often have the first opportunity to assess a resident in an LTCF. Jackson and Schafer ${ }^{41}$ surveyed 50 CNAs 
and asked which symptoms or signs of pneumonia warranted notification of the charge nurse. For temperature elevation, cough, and shortness of breath, the response rates were $30 \%, 24 \%$, and $12 \%$, respectively. These investigators then determined the agreement/disagreement between GNPs (the number is not specified in the paper) and CNAs regarding the presence of infection. There were 110 assessments made among 75 nursing facility residents. In 76 instances $(69 \%)$, both groups agreed that there was no infection, and in $4 \%$ of assessments, both groups agreed that an infection was present. However, in the remaining $27 \%$ of assessments, there was disagreement between the GNPs and CNAs about whether infection was present or absent or about the type of infection; CNAs often attributed any symptoms and signs to "colds," even when the GNPs found UTIs, skin infections, and pneumonia. The final diagnoses were not confirmed by a physician.

To our knowledge, no studies have compared LPNs, RNs, advance-practice nurses, or physician assistants with physicians or have examined the impact of specific training on the ability of CNAs to correctly identify infections. Several authors suggest the use of specific protocols to assist nurses and GNPs with evaluation of fever, ${ }^{23,43}$ but information on the utility of such protocols in LTCF residents has not been published. Thus, at present, the role of CNAs is to recognize and report significant changes in the clinical condition of LTCF residents or abnormalities in vital signs; the role of physician extenders and physicians is to initiate appropriate diagnostic and therapeutic interventions.

\section{WHAT CLINICAL EVALUATION SHOULD BE PERFORMED FOR AN LTCF RESIDENT WITH SUSPECTED INFECTION?}

\section{Recommendation}

5. Initial clinical evaluation should involve assessment of respiratory rate, hydration status, mental status, oropharynx, conjunctiva, skin (including sacral, perineum, and perirectal areas), chest, heart, abdomen, and indwelling devices (if present) (B-III).

\section{Evidence Summary}

No specific studies have addressed the utility of a focused history and physical examination, but a general approach to the clinical evaluation of fever in residents of LTCFs can be suggested on the basis of the most likely sources of infection. ${ }^{44,45}$ Attention should be directed toward the following: mental status, oropharynx, conjunctiva, skin (including turning the patient to look for pressure ulcers), chest, heart, abdomen, perineum and perirectal area, and CNS. ${ }^{44}$ Several groups have outlined general guidelines for evaluation of suspected infection, including clinical recommendations. ${ }^{25,26,45}$ Although these guidelines have not been validated, they represent a consensus of representatives from various organizations interested in or involved with care of LTCF residents with infection.

An English study from the 1980s suggested that a respiratory rate of $>25$ breaths/min was both sensitive and specific for diagnosis of pneumonia. ${ }^{46}$ In an observational study of 87 English LTCF residents, the normal respiratory rate was $16-25$ breaths/min. In a follow-up prospective study of 60 consecutive residents acutely admitted to a geriatric unit, pneumonia was diagnosed in 21 (35\%), 19 $(90 \%)$ of whom had respiratory rates of $>25$ breaths/min. The respiratory rate of 12 residents with UTIs were not elevated, and of those residents without infection, only 1 of 27 had a respiratory rate of $>25$ breaths/min. However, in a study of 2,334 residents of 36 Missouri nursing homes who were evaluated for a possible lower RTI, $19 \%$ of those with no radiographic evidence of pneumonia had a respiratory rate of $\geq 30$ breaths $/ \mathrm{min} .{ }^{32}$

Dehydration commonly accompanies fever in elderly residents of LTCFs; this is perhaps a result of impaired vasopressin responses in elderly subjects. ${ }^{47,48}$ In a study of 40 febrile residents in a hospital-based LTCF, ${ }^{49} 24(60 \%)$ had evidence of hypernatremia and/or an elevated ratio of blood urea nitrogen level to serum creatinine level. Most of the 40 residents had UTI, urosepsis, or pneumonia, but a significant proportion $(25 \%)$ had an upper respiratory viral syndrome. No single physical finding is of particular value in assessing dehydration, ${ }^{49,50}$ although tongue dryness, tongue furrows, and dry mucous membranes provide the best correlation. In one study, ${ }^{49}$ a reference in the chart by staff regarding poor oral intake was observed in 11 residents, and $9(82 \%)$ were found to be dehydrated according to the laboratory criteria noted above. Thus, LTCF residents with poor oral intake are likely to be at enhanced risk for dehydration in the setting of fever, and this historic clue may indicate a population in whom baseline electrolyte, blood urea nitrogen, and serum creatinine determinations are of particular importance. In addition, medications such as diuretics may lead to dehydration and hence, drug evaluation is important.

In LTCF residents, special attention should be noted for specific underlying disorders or conditions that predispose them to select infections, such as diabetes mellitus (a predisposition for skin infection and UTI), chronic obstructive pulmonary disease (for pneumonia), poor swallowing or gag reflex (for aspiration pneumonia), long-term indwelling urinary catheters (for UTI), prosthetic devices (e.g., artificial joints leading to septic arthritis), altered mental status (for aspiration pneumonia), or chronic immobility (for pressure ulcers). For example, the presence of an indwelling bladder catheter is associated with a 39 -fold increase in the risk of bacteremia over a 1 -year period in residents of LTCFs. ${ }^{43}$

\section{Adequacy of the Clinical Evaluation of Fever in LTCFs}

Several studies suggest that fever is inadequately evaluated or, at the very least, inadequately documented in residents of LTCFs. In one study, 241 infections were identified among 227 residents in LTCFs in Maryland. ${ }^{51}$ The criteria for all infections included measurement of temperature, examination by a physician, and microbiologic culture of specimens from the suspected sites; a chest radiograph was considered to be appropriate for all those who had pneumonia or were suspected of having pneumonia or for those who had fever without a clear source. On the basis of these criteria, only $21 \%$ of residents with infection were "appropriately" evaluated. Pneumonia was the most likely infection to be adequately evaluated $(53 \%)$. When the same records ${ }^{51}$ were reviewed regarding antibiotic use, it was found that RNs and LPNs examined $36 \%$ of residents for 
whom antibiotics were prescribed, that $47 \%$ of residents were assessed by physicians, and that the remaining $17 \%$ were not examined before the prescription of antibiotics. ${ }^{52}$ Some of the lack of evaluation and intervention may reflect conscious decisions of the health providers neither to assess nor to treat the more debilitated residents; ${ }^{53}$ it is also possible that the standards of evaluation of acute care facilities may influence the criteria and decisions on appropriateness of care of residents in LTCFs.

Advance directives may greatly impact the initiation or extent of evaluation in febrile episodes in LTCF residents. It has been reported that evaluation and antibiotic treatment were provided far less often to "comfort care only" residents with UTI, RTI, or skin infections. ${ }^{54}$ However, some data suggest that there are distinct differences of evaluation based not just on advance directives but also on the type of care facility. None of the procedures (including a physical examination) outlined as "appropriate" were performed for $71(31 \%)$ of the 227 patients noted above; ${ }^{51}$ however, the definition of "appropriate" was based on the opinion of practitioners who more often practice in a hospital setting, and this definition may not be accurate for evaluation of fever in persons in LTCFs. A multivariate analysis of factors contributing to "no evaluation" in that study showed that dementia, residing in a larger facility ( $>150$ beds), and residing in an urban facility were significantly associated with an absence of a medical evaluation.

It has also been suggested that the type of facility influenced fever evaluation: a quicker response to persons with fever and more thorough assessment and treatment were found in hospital- based nursing homes (where there was more physician involvement) than in community-based nursing homes. ${ }^{55}$ However, no difference was noted with regard to outcome in hospital-based versus communitybased homes (survival rates were $87 \%$ and $88 \%$, respectively; early mortality rates were $3 \%$ and $4 \%$, respectively; and the percentages of patients who were transferred to a hospital were $11 \%$ and $8 \%$, respectively). Thus, it is not clear whether evaluation of fever in residents of LTCFs by a physician alters outcome.

\section{HOW CAN LTCF STAFF EFFECTIVELY COMMUNICATE ABOUT POSSIBLE INFECTION WITH CLINICIANS WHO WILL BE MAKING TREATMENT DECISIONS?}

\section{Recommendations}

6. Information should be relayed to the responsible advancepractice nurse, physician assistant, or physician for decisions regarding further evaluation (B-III).

7. The full extent of the clinical evaluation should be documented as part of the medical record. If specific diagnostic measures are consciously withheld, the reasons should be recorded (B-III).

\section{Evidence Summary}

Long-term care staff often need to communicate among themselves and, subsequently, with a clinician (physician, nurse practitioner, or physician assistant) to initiate patient evaluation and management. Clinician access for timely direct patient assessment of fever or other symptoms remains a vexing problem for many LTCFs. Consequently, fever is a common antecedent to the decision to transfer patients to a higher level of care. Although direct care staff often make the initial clinical observations, calls to clinicians are typically made by supervising staff (an LPN or $\mathrm{RN}$ ), because they are the ones licensed to take physician orders over the telephone. Multiple issues can impede effective communication about a possible infection in a facility or with a clinician, such as failure to communicate a change in condition at a shift change, difficulty contacting an on-call physician after hours, or a difficult relationship between a nurse and a physician. ${ }^{56}$ Skills of direct care staff in recognizing symptoms of infection and communicating them to a supervisor may be influenced by experience, education, and language skills (for nonnative speakers). The LPN or RN should independently assess the resident to be certain that key information on the resident's condition is available when the nurse calls the clinician. Clinicians practicing in the LTCF need to participate in setting and reinforcing standards for consistent collection and reporting of clinical information, so that adequate detail is communicated when there are overt or subtle signs suggesting an infection or other acute change in condition. Acute or subacute changes in functional status, such as new urinary incontinence, falls, decreased oral intake, or delirium, may be the initial and/or only clinical manifestation of infection in elderly persons. ${ }^{5}$

When calling the clinician, certain minimum information should be available to report at the time of the call. In addition to vital signs and acute or subacute changes in functional status, depending on the presenting symptom, a directed review of systems will help with an over-the-phone determination of what needs to be done next. Presence of a urinary catheter or any other indwelling device (e.g., vascular devices) should always be reported, along with whether entry sites are erythematous or tender. Similarly, staff should report breathlessness and cough (or a change in these if chronically present), most recent bowel movement and its character, and any urinary symptoms. Assessment should also include the following: an assessment of respiratory status, including use of accessory muscles, retractions, and quality of breath sounds; presence of bowel sounds; and any wounds or areas of tenderness or redness. Any abnormal vital signs should be repeated. An example of what should be reported for a variety of conditions can be found in the American Medical Directors Association patient evaluation guideline. ${ }^{57}$ An independent consensus panel has suggested that pneumonia be considered a possible diagnosis if $\geq 2$ of several respiratory and general illness signs are present and that their presence should trigger immediate nursing home communication with a clinician and a prompt response. ${ }^{58}$

\section{WHAT LABORATORY TESTS SHOULD BE ORDERED FOR THE LTCF RESIDENT WITH SUSPECTED INFECTION?}

\section{Initial Diagnostic Testing Recommendations}

8. Advance directives for residents should be reviewed prior to any intervention; if not prohibited by such di- 
rectives, initial diagnostic tests for suspected infection can be performed in the LTCF if resources are available and if studies can be done in a timely manner (B-III).

\section{Evidence Summary}

There are several site-specific considerations that must be addressed in making recommendations for diagnostic laboratory and radiologic tests for suspected infections in LTCF residents.

Appropriate diagnostic tests for evaluation of fever and infection in LTCF residents have not been established and, when recommended, have not been systematically studied. ${ }^{25,45}$ Furthermore, the guidelines from "expert panels," including physicians with experience in LTCFs, are often influenced by diagnostic standards used routinely in acute care settings (e.g., site-specific bacterial cultures for suspected skin infection, UTI, and lower RTIs and urine and blood cultures for fever of unknown source). ${ }^{51,59}$ However, obtaining specimens adequate for microbiologic studies in LTCFs can be problematic. Residents suspected of having an RTI may not be able to produce expectorated sputum. When respiratory secretions are available, they may be misleading, because sputum samples or nasopharyngeal aspirate specimens are often contaminated with respiratory pathogens that colonize the oropharynx. ${ }^{60}$ Although urine specimens are more frequently obtained, the prevalence of asymptomatic bacteriuria is $15 \%-50 \%$ in noncatheterized LTCF residents and is essentially $100 \%$ in residents with long-term urinary catheters. ${ }^{61-63}$ Thus, some diagnostic tests with poor positive and negative predictive values must be accepted in the evaluation of LTCF residents suspected of having infection.

Infectious diseases physicians with considerable experience in LTCFs have noted that clinicians must weigh the benefits of diagnostic tests versus their direct costs. This is especially relevant for LTCFs operating under the current Prospective Payment System. These physicians recommend that tests only be performed if they have a reasonable diagnostic yield, are of low risk, are reasonable in cost, and improve patient management. If a test will not cause the clinician to reassess his or her treatment strategy, then there is little justification for ordering the laboratory examination. ${ }^{64}$ Others with similar expertise and experience have noted that additional diagnostic tests should be performed only for clinical presentations or manifestations that are unusual or that fail to respond to initial therapy or in circumstances in which prolonged antimicrobial therapy is considered. ${ }^{65}$ Moreover, explicit plans (or as implied by directives to limit interventions) to not perform or to limit diagnostic studies in severely debilitated or ill residents with poor survival prognosis shall always be considered to be appropriate, unless a risk is posed to other residents and staff. ${ }^{54}$

\section{Blood Cell Count \\ Recommendations}

9. A CBC count, including peripheral WBC and differential cell counts (preferably a manual differential to assess bands and other immature forms), should be performed for all LTCF residents who are suspected of having infection within $12-24 \mathrm{~h}$ of onset of symptoms (or sooner, if the resident is seriously ill), consistent with local standards of practice (B-II).

10. The presence of an elevated WBC count (WBC count, $\geq 14,000$ cells $/ \mathrm{mm}^{3}$ ) or a left shift (percentage of band neutrophils or metamyelocytes, $>6 \%$; or total band neutrophil count, $\geq 1,500$ cells $/ \mathrm{mm}^{3}$ ) warrants a careful assessment for bacterial infection in any LTCF resident with suspected infection, with or without fever (B-II).

11. In the absence of fever, leukocytosis and/or left shift, or specific clinical manifestations of a focal infection, additional diagnostic tests may not be indicated, because of the low potential yield (C-III). Nonbacterial infections, however, cannot be excluded.

\section{Evidence Summary}

Suspected Symptomatic Infection in LTCF Residents. Provided that there are no prior directives (in advance or currently expressed by the resident or caregiver) limiting diagnostic or therapeutic medical interventions, all residents in LTCFs with suspected symptomatic infection should have appropriate diagnostic laboratory studies performed promptly, provided that the tests have reasonable yield, are of low cost and risk, and may improve the resident/patient management. Findings should be discussed with the primary care clinician as soon as results are available.

$C B C$ Count with Differential. In a prospective cohort analytic study of $>200$ older persons who presented to a community-based hospital emergency department, 33 persons had documented bacterial infection, including $\sim 50 \%$ of persons with no fever. ${ }^{66}$

Evaluation of the total WBC count (with leukocytosis defined as a leukocyte count $\geq 14,000$ cells $/ \mathrm{mm}^{3}$ ), number of band forms, and the percentage of neutrophils and band forms revealed that an elevated total band count $\left(\geq 1,500\right.$ cells $\left./ \mathrm{mm}^{3}\right)$ had the highest likelihood ratio (14.5) for detecting documented bacterial infection; an increase in the percentage of neutrophils $(\geq 90 \%)$ and band neutrophils ( $>6 \%$; i.e., left shift) had likelihood ratios of 7.5 and 4.7, respectively. Leukocytosis with a leukocyte count $\geq 14,000$ cells $/ \mathrm{mm}^{3}$ had a likelihood ratio of 3.7. Thus, this study and others ${ }^{67,68}$ demonstrate that there is a high probability of an underlying bacterial infection in an older person if the WBC count is elevated, with or without fever; has a high percentage of neutrophils or left shift (even in the presence of a normal total leukocyte count-i.e., $<10,000$ cells $/ \mathrm{mm}^{3}$ ); or shows an elevated total band count. In observational studies, leukocytosis has been associated with increased mortality among LTCF residents with nursing home-acquired pneumonia (WBC count, $>15,000$ cells $/ \mathrm{mm}^{3}$ ) and bloodstream infection (WBC count, $>20,000$ cells $\left./ \mathrm{mm}^{3}\right) .69,70$

\section{Urinalysis and Urine Culture Recommendations}

12. Urinalysis and urine cultures should not be performed for asymptomatic residents (A-I).

13. In noncatheterized residents, the diagnostic laboratory evaluation of suspected UTI should be reserved for those with acute onset of UTI-associated symptoms 
and signs (e.g., fever, dysuria, gross hematuria, new or worsening urinary incontinence, and/or suspected bacteremia) (A-II).

14. In residents with long-term indwelling urethral catheters, evaluation is indicated if there is suspected urosepsis (i.e., fever, shaking chills, hypotension, or delirium), especially in the context of recent catheter obstruction or change (A-II).

15. Appropriately collected urine specimens include a midstream or clean-catch specimen obtained from elderly men who are cooperative and functionally capable; however, it is often necessary to use a freshly applied, clean condom external collection system, with frequent monitoring of the urine bag (B-II). Specimen collection from women will often require an in-and-out catheterization (B-III).

16. Residents with long-term indwelling urethral catheters and suspected urosepsis should have catheters changed prior to specimen collection and institution of antibiotic therapy (A-II).

17. The minimum laboratory evaluation for suspected UTI should include urinalysis for determination of leukocyte esterase and nitrite level by use of a dipstick and a microscopic examination for WBCs (B-II). If pyuria (>10 WBCs/high-power field) or a positive leukocyte esterase or nitrite test is present on dipstick, only then should a urine culture (with antimicrobial susceptibility testing) be ordered (B-III).

18. If urosepsis is suspected, urine and paired blood specimens should be obtained, if feasible, for culture and antimicrobial susceptibility testing, and a Gram stain of uncentrifuged urine should be requested (B-III).

\section{Evidence Summary}

Symptomatic UTI in LTCF residents may present as fever and clinical pyelonephritis or as irritative symptoms (e.g., dysuria, frequency, urgency, nocturia, and increased incontinence). ${ }^{17,62}$ The evaluation of these symptoms and signs is difficult, because they are frequently observed in residents and are not necessarily associated with bacteriuria $\left(>10^{5} \mathrm{cfu} / \mathrm{mL}\right)$ or altered with antimicrobial therapy. ${ }^{71}$ The majority of elderly persons with bacteriuria are asymptomatic. ${ }^{17,62,72}$ Moreover, residents are often treated for UTIs when nonspecific symptoms, including low-grade fever, increased confusion, incontinence, anorexia, or functional decline, are noted, but limited studies suggest that these symptoms may not be associated with UTIs. ${ }^{27}$

Residents who are suspected of harboring an infection will often undergo urinalysis and urine culture as part of the evaluation to determine the cause of infection. These tests, however, frequently demonstrate bacteria because of the noted high prevalence $(10 \%-50 \%)$ of asymptomatic bacteriuria. ${ }^{61,62}$ Prospective studies have shown that untreated asymptomatic bacteriuria in LTCF residents without longterm indwelling urinary catheters persist for as long as 1-2 years without evidence of increased morbidity or mortality. ${ }^{73,74}$ Microscopic pyuria ( $\geq 10 \mathrm{WBC}$ /high-power field of spun urine) or a dipstick test positive for leukocyte esterase are not highly predictive of bacteriuria, but the absence of pyuria or even a dipstick test negative for leukocyte esterase and nitrite can exclude bacteriuria (i.e., the negative predictive value approaches $100 \%) .{ }^{75-78}$ In persons with neutropenia or, on rare occasions, with a normal peripheral WBC count, significant bacteriuria may occur without pyuria. Thus, although the presence of pyuria has a relatively low predictive value for UTI, both a negative urinalysis for WBCs and dipstick tests for leukocyte esterase and nitrite are useful to exclude a urinary source for a suspected infection. However, in residents suspected of having urosepsis because of, for example, high fever, shaking chills, and hypotension, urine culture is recommended along with blood culture. For residents with new indwelling urinary catheters, catheter- associated UTI, defined as new pyuria and bacteriuria, develops on average within 4 days and are rarely symptomatic. ${ }^{79}$ In residents with chronic indwelling urinary catheters, the presence of bacteriuria and pyuria is virtually universal. For residents with long-term indwelling urethral catheters, fever, and symptomatic UTI, a prospective randomized trial of 54 nursing home residents demonstrated that replacement of the catheter prior to the institution of antimicrobial therapy was associated with improved clinical outcomes. ${ }^{80}$

Frail elderly LTCF residents are often unable to provide a midstream voided urine specimen for diagnostic testing. For men, it is frequently necessary to apply a clean condom external collection device. However, this validated method for urine collection requires carefully trained personnel and frequent monitoring of the urine bag. ${ }^{81}$ If appropriately collected voided urine cannot be obtained from women, in-and-out catheterization should be used to obtain urine specimens for culture. ${ }^{62}$ The benefit of antimicrobial or antiseptic coated catheters in LTCF residents has not been directly assessed.

\section{Blood Culture \\ Recommendation}

19. In a study of older adult nursing home residents, blood cultures were demonstrated to have a low yield and rarely to influence therapy; thus, they are not recommended for most residents of LTCFs (B-II) (note: this may not apply to all types of residents or all types of LTCFs). Blood cultures may be appropriate for residents in whom bacteremia is highly suspected and if the LTCF has quick access to laboratory facilities, adequate physician coverage to respond to positive culture results, and a capacity to administer parenteral antibiotics.

\section{Evidence Summary}

Bacteremia is documented infrequently in LTCFs, with an incidence of 5-40 episodes per 100,000 resident-days; ${ }^{82}$ the proportion of infections complicated by secondary bacteremia in this setting is $\sim 6 \% .{ }^{83}$ These rates were documented primarily in large LTCFs (often associated with Veterans Affairs medical centers) with full-time medical staff and 24-h on-site physician coverage; there are no comparable studies reported from the more representative smaller proprietary or the not-for-profit community-based LTCFs.

As expected, the most frequent sites of infection with LTCF-acquired bacteremias are as follows: the urinary tract $(50 \%-55 \%)$, the respiratory tract $(10 \%-11 \%)$, skin or soft 
tissue $(\sim 10 \%)$, intra-abdominal foci $(\sim 5 \%)$, infected intravenous catheters $(\sim 3 \%)$, and unknown site $(15 \%-$ $22 \%) .{ }^{83}$ The overall mortality rates associated with bacteremia in LTCF residents range from $18 \%$ to $50 \%$; the highest rates are for patients with bacteremic pneumonia. ${ }^{70,83,84}$ Despite appropriate therapy, $\sim 50 \%$ of deaths occur within $24 \mathrm{~h}$ after the diagnosis of bacteremia. ${ }^{83}$

In retrospective studies, nonspecific symptoms, such as lethargy, confusion, falls, abdominal pain, nausea, vomiting, and incontinence, are frequently noted in older persons at the onset of documented bacteremia. ${ }^{85}$ Fever $\left(\geq 100^{\circ} \mathrm{F}\right.$ $\left.\left[\geq 37.8^{\circ} \mathrm{C}\right]\right)$ is usually present in bacteremic older persons; in 1 series, however, $15 \%$ of older persons had "afebrile" bacteremia, including many of the nosocomial bacteremias for which they were already receiving antimicrobial therapy. ${ }^{68}$ In a prospective study, older patients in a geriatric hospital had predictors of bacteremia, with higher relative risks (3.4-15.7) than was noted for nonbacteremic older patients. These predictors were: fever (temperature, $>101.3^{\circ} \mathrm{F}\left[>38^{\circ} \mathrm{C}\right]$ ), in community-acquired cases only; bladder catheter removal, in hospital-acquired cases only; and shaking chills, shock, total band neutrophil count $\geq 1,500$ cells $/ \mathrm{mm}^{3}$, and lymphocyte count $<1,000$ cells/ $\mathrm{mm}^{3}$ in both groups. ${ }^{86}$ A prospective observational study of elderly adults (3\% of whom were from LTCFs; C. L. Chen, personal communication) with bloodstream infection found that, although the elderly persons were less likely to present with fever or tachycardia, they were more likely to have acute renal failure or respiratory failure, compared with younger adults (age, $<65$ years). ${ }^{87}$ Other studies, using case-control methods in hospital and emergency department settings, however, have also noted that older bacteremic patients have fewer symptoms or signs than do younger bacteremic patients and that clinical indicators alone are unreliable predictors of bacteremia in older patients. ${ }^{88,89}$ In a retrospective study of 166 cases of nursing home-acquired bloodstream infection among patients who were subsequently hospitalized, predictors of mortality were pulmonary source of infection, hypotension, and leukocytosis (leukocyte count, $>20,000$ cells $/ \mathrm{mm}^{3}$ ). ${ }^{90}$

Blood cultures could potentially be helpful in establishing a definitive microbiologic diagnosis in LTCF residents with selected conditions, such as (1) suspected polymicrobial bacteremia in older residents with probable urosepsis and long-term indwelling urethral catheters or in those with infected pressure ulcers, ${ }^{59}$ (2) suspected urosepsis when polymicrobial bacteriuria is present, ${ }^{59}$ or (3) suspected pneumonia (or other suspected bacterial infections) when the resident appears ill enough to warrant hospitalization but will be cared for in the LTCF. ${ }^{37}$ Blood samples should be obtained for cultures prior to transfer to an acute care facility, if feasible. Although obtaining blood samples for culture within $24 \mathrm{~h}$ after presentation has been associated with improved 30-day survival in communityacquired pneumonia, ${ }^{90}$ there are no comparable studies in LTCFs. However, because of the high mortality rates within $24 \mathrm{~h}$ after onset and because $50 \%$ of deaths among nursing home residents with positive blood culture results occur within the first 3 days after onset, it is doubtful that blood cultures would significantly impact mortality risk for most nursing home residents, and they would provide little opportunity for starting or adjusting effective antimicrobial therapy. ${ }^{70,91}$ Blood cultures may be appropriate if the LTCF has quick access to laboratory facilities, adequate physician coverage to respond to positive culture results, and capacity to administer parenteral antibiotics.

\section{Pneumonia Evaluation}

If pneumonia is clinically suspected and resources are available, the following diagnostic studies should be performed.

\section{Recommendations}

20. Pulse oximetry should be performed for residents with respiratory rates of $>25$ breaths/min, to document hypoxemia (oxygen saturation, $<90 \%$ ) in residents with suspected pneumonia and to guide transfer to an acute care facility pending the resident's or family's wishes (B-II).

21. Chest radiography should be performed if hypoxemia is documented or suspected, to identify the presence of a new infiltrate compatible with acute pneumonia and to exclude other complicating conditions (e.g., multilobe infiltrates, large pleural effusions, congestive heart failure, or mass lesions) (B-II).

\section{Evidence Summary}

Pulse Oximetry. Hypoxemia (arterial oxygen partial pressure, $<60 \mathrm{mmHg}$ ) is one of the important indicators in the Pneumonia Prognosis Index of acute severity and shortterm mortality for patients with community-acquired pneumonia, which included residents with LTCF-acquired pneumonia. ${ }^{92}$ This index has been further validated in nursing home populations. ${ }^{93}$ In a prospective cohort study of risk factors for 30-day mortality in nursing home residents with lower RTI, oxygen saturation of $<90 \%$ was associated with higher mortality rate in bivariable analysis but was not part of a multivariate prediction model. However, the oxygen saturation value was missing in the majority of cases evaluated; this may have affected its significance in a multivariate model. ${ }^{32}$ More recently, oxygen saturation of $<90 \%$ was a strong predictor of hospitalization but was not significantly associated with mortality in a nested cohort study of nursing home pneumonia in residents of nine Ontario, Canada, nursing homes. ${ }^{94}$ Hypoxemia is a predictor of impending respiratory failure requiring intensive care unit admission. ${ }^{95}$ Impending respiratory failure can be suspected at the bedside if the patient has a respiratory rate of $>25$ breaths $/ \mathrm{min}$, and it can be confirmed by an oxygen saturation of $<90 \%$ on pulse oximetry, as advised in the recent modification and validation study of the Pneumonia Prognosis Index in nursing home residents. ${ }^{93}$ Finally, in febrile nursing home residents, pulse oximetry may also assist in differentiating pneumonia from other infectious processes. A case-control study comparing nursing home residents with pneumonia versus residents with other infections found that an oxygen saturation of $<94 \%$ had a sensitivity of $80 \%$, specificity of $91 \%$, and positive predictive value of $95 \%$ for diagnosis of pneumonia. ${ }^{96}$

Chest Radiographs. An abnormal chest radiograph demonstrating a new infiltrate compatible with pneumonia is often considered to be the most reliable method of diagnosing suspected LTCF-acquired pneumonia. ${ }^{18,25,28,45,51}$ More recently, radiographic diagnosis of pneumonia in 
nursing homes was associated with both death and hospitalization. ${ }^{94}$ However, practice patterns in LTCFs show considerable variability with respect to performing chest radiographs, ranging from $20 \%$ to $35 \%$ in communitybased nursing facilities $45,51,64$ to as high as $85 \%$ in university medical center-affiliated nursing facilities. ${ }^{97}$

Although most LTCFs have contract services to provide chest radiography, several problems remain, including (1) the inability of frail older persons to maintain a stationary, upright sitting position; (2) the relatively poor quality of portable radiography techniques (compared with standard techniques using the posterior-to-anterior projection); and (3) a lack of availability of previous films for comparison. Despite these concerns, evidence of acute pneumonia is present on $75 \%-90 \%$ of chest radiographs obtained for residents with suspected LTCF-acquired pneumonia. ${ }^{45,97}$ However, there are no prospective trials evaluating the impact of chest radiography on outcomes of LTCF-acquired pneumonia.

The clinical diagnosis of pneumonia can be exceedingly difficult. ${ }^{98}$ Excluding bacteremia from all sources, pneumonia is the only infection that is an important contributor to mortality for residents in LTCFs; ${ }^{82}$ thus, it is important to document this serious condition by chest radiography whenever possible. Moreover, the chest radiograph may demonstrate other high-risk conditions (e.g., multilobe infiltrate, congestive heart failure, large pleural effusions, and mass lesions) that should warrant considering for transfer to an acute care facility, depending on the wishes of the resident or their family or caregiver.

Respiratory Secretions. The diagnosis of suspected pneumonia in LTCF residents is usually based on clinical criteria alone (e.g., fever, tachypnea [ $>25$ breaths/min], and new or increased cough with purulent respiratory secretions). ${ }^{44}$ Retrospective studies of nursing-facility practices indicate that sputum examinations are ordered for only $5 \%-10 \%$ of residents with the diagnosis of pneumonia. ${ }^{51,97}$ Even in carefully performed prospective studies of radiographically confirmed LTCF-acquired pneumonias, using recommended methods for screening prior to culture of expectorated sputum, sputum samples are obtained from $<30 \%$ of residents; ${ }^{28}$ when sputum is obtained, $<50 \%$ of specimens demonstrate $<25$ squamous epithelial cells/lowpower field on microscopic examination of Gram-stained specimens. ${ }^{99}$ In addition, the single-most frequent causative agent $(\sim 35 \%)$ is "mixed flora" (i.e., $\geq 2$ respiratory pathogens or normal throat flora only). ${ }^{100}$ No prospective studies have been done to determine whether a more rigorous microbiologic study of respiratory secretions will lead to improved outcomes (i.e., cure, a reduced number hospital transfers, or a patient still alive 30 days after diagnosis of pneumonia). In a retrospective study of 99 nursing home-acquired pneumonias in a single large nursing home with on-site bacteriology testing facilities, only 14 adequate sputum samples were obtained. Although the overall 30day mortality rate for the cohort was $10 \%$, none of the residents from whom a sputum sample was obtained died within 30 days, suggesting that the ability to obtain sputum may actually be a marker for better outcomes or higher functional status. ${ }^{101}$

Urinary Antigen Testing. There are few specific data on LTCF residents regarding the performance characteris- tics of urinary antigen testing to detect Streptococcus pneumoniae or Legionella pneumophila (serogroup I), the 2 pathogens for which U.S. Food and Drug Administrationapproved test kits are available. Thus, specific recommendations cannot be provided. However, the tests may be useful in LTCF residents in selected circumstances, particularly if sputum specimens cannot be obtained. Older adults have been included in studies of hospitalized patients with pneumonia. The sensitivity of urinary antigen testing for $S$. pneumoniae in those studies was $\sim 75 \%$, whereas the specificity approached $90 \%$. Performance characteristics are similar for L. pneumophila, but it is important to recognize that only serogroup I is detected by this test, and the sensitivity may be lower for nosocomial legionellosis (and, by implication, perhaps also in LTCF residents), even when illness is caused by serogroup I. ${ }^{102}$ Several studies have examined the utility of Legionella urinary antigen tests in outbreak settings and for diagnosis of legionellosis in regions where it is highly endemic (e.g., western Pennsylvania). The proportion of LTCF-associated cases of pneumonia caused by L. pneumophila ranged from $0 \%$ to $6.5 \%$; thus, the organism is relatively rare even in areas in which community-acquired legionellosis is common. It is likely that Legionella urinary antigen testing would prove to be most useful in LTCF outbreaks of pneumonia due to unclear etiology. ${ }^{103}$

\section{Respiratory Viral Infection Evaluation Recommendation}

22. At the onset of a suspected respiratory viral infection outbreak, nasopharyngeal wash or swab samples obtained from the throat and nasopharynx (combined with refrigerated viral transport media in a single tube) should be obtained from several acutely ill residents for transport to an experienced laboratory for virus isolation and rapid diagnostic testing for influenza $\mathrm{A}$ virus and other common viruses (A-III).

\section{Evidence Summary}

Influenza is the most serious viral respiratory infection for older persons; clusters or outbreaks of influenza occur frequently in LTCFs, with attack rates ranging from $20 \%$ to $70 \%$. During outbreaks, complication rates among unvaccinated residents of LTCFs are substantial, approaching $32 \%$ (range, $5-84 \%$ ); $7 \%$ (range, $5 \%-42 \%$ ) pneumonia, including pneumonia due to methicillin-resistant $S$. aureus; $4 \%$ (range, $3 \%-26 \%$ ) hospitalization; and $4 \%$ (range, $0 \%$ $73 \%$ ) death. ${ }^{104}$ Recent studies suggest that the consequences of respiratory syncytial virus infection are just as severe in older populations. ${ }^{105-107}$

The diagnosis of influenza and respiratory syncytial virus infection is frequently made on the basis of clinical and epidemiologic findings during a community outbreak. However, additional diagnostic efforts are warranted in LTCF outbreaks, because of the increased frequency of other respiratory viruses that can cause severe illness in this setting (e.g., parainfluenza virus, metapneumovirus, coronaviruses, and rhinoviruses). ${ }^{107,108}$

Of all the respiratory viruses mentioned, influenza virus is the most easily detected. In frail elderly patients, spec- 
imens for viral isolation by culture are best obtained by nasopharyngeal swab, because it is simpler to perform, with acceptable sensitivity, compared with nasopharyngeal wash. ${ }^{108,109}$ The swabs are combined in a single refrigerated tube containing viral transport media and are transported (preferably on ice and within 1-2 $\mathrm{h}$ after collection) to an experienced laboratory for viral culture and rapid diagnostic testing. ${ }^{108,110}$ However, not all LTCFs will find it feasible to obtain and transfer the specimens. Of all the respiratory viruses mentioned, influenza is the most readily isolated by culture technique, particularly if the specimen is obtained within $24-48 \mathrm{~h}$ after onset of clinical illness. ${ }^{108}$ In general, rapid antigen testing for respiratory viruses in adults has been insensitive. For influenza, the sensitivity of rapid antigen tests has ranged from $40 \%$ to $80 \%$, with specificity of $\geq 85 \% .{ }^{108,109}$ However, confirmation of influenza in LTCFs by rapid testing assisted with decisions about isolation and initiation of antiviral prophylaxis, with significant reductions in duration of the outbreak and hospitalization costs. ${ }^{111}$ Very sensitive and specific RT-PCR tests for multiple respiratory viruses are available but expensive. ${ }^{108,109}$

\section{Evaluation of SSTI}

\section{Recommendations}

23. Bacterial cultures should be performed only under select conditions. Surface swab cultures are not indicated for the diagnosis of most bacterial SSTIs (A-II), with the exception of conjunctivitis (B-III). Needle aspiration (only skilled physicians should perform this procedure) or deep-tissue biopsy to obtain samples for Gram stain and culture may be appropriate in special circumstances in which unusual pathogens are suspected, fluctuant areas suggest an abscess is present, or initial antimicrobial treatment has been unsuccessful (C-III).

24. If a pressure ulcer demonstrates poor healing and/or persistent purulent drainage, obtain deep specimens for culture of tissue and bone specimens at the time of surgical debridement or biopsy (B-II). MRI is the most sensitive imaging modality to detect osteomyelitis, but bone biopsy for histopathologic examination definitively confirms the diagnosis and is most useful in guiding antimicrobial therapy (A-III).

25. For suspected mucocutaneous fungal infection, a scraping can be performed for potassium hydroxide $10 \%$ preparation to verify the presence of yeast or dermatophytes (B-III). If mucocutaneous candidiasis is refractory to empirical treatment, culture can be performed for the detection of drug-resistant species (B-III).

26. For suspected herpes simplex or herpes zoster, skin scrapings may be examined for the presence of giant cells (Tzanck preparation) and/or sent for culture, immunofluorescent viral antigen studies, or PCR (A-III).

27. Scabies should be considered in any nursing home resident with a generalized rash that is unexplained. Diagnosis should be attempted by light microscopy demonstration of mites, eggs, or mite feces on mineral oil preparations of several scrapings (B-III). If proper diagnostic equipment is not available and if clinical experience with scabies is limited, consider consulta- tion with a dermatologist to inspect or obtain scrapings from suspected persons (C-III).

\section{Evidence Summary}

SSTI is the third most common infection seen in LTCFs; rates of $1 \%-9 \%$ and a prevalence of $0.9-2.1$ cases per 1,000 patient-days have been reported. ${ }^{112}$ SSTI typically results when breaks in skin or mucosa occur as a consequence of physical trauma, maceration, pressure, or use of devices. Wounds may become secondarily infected with pathogens found among the resident's own endogenous flora or exogenously via the hands of personnel, from other residents, or by contact with contaminated environment or fomites.

Although bacteria are the most common causes of SSTI in LTCF residents, viruses, fungi, and parasites must also be considered. The 3 most common types of SSTI in LTCF residents include cellulitis, infected pressure ulcer, and scabies. Primary infections of skin and mucosa, reactivation of latent herpetic infection, ectoparasitic infection, and secondary infection of pressure ulcers also occur.

Primary SSTI. The primary SSTIs seen in LTCF residents include erysipelas, cellulitis, folliculitis, and impetigo. Primary infections of deep soft tissue involving fascia and muscle rarely occur and typically do so as part of an outbreak. Common bacterial etiologies of primary SSTI include S. aureus and beta-bhemolytic streptococci, especially Streptococcus pyogenes. Diagnosis and treatment decisions are made primarily on the basis of clinical characteristics. When the presentation is atypical or the patient is not responding to empirical therapy, Gram stain and culture of pus, blister fluid, or deep-tissue specimens can be useful to confirm a bacterial cause and antimicrobial susceptibilities. ${ }^{113,114}$

Secondary SSTI. Twenty percent of nursing home residents will develop secondary infection of a pressure ulcer within 2 years after admission; $6 \%$ of those ulcers will become infected, at a rate of 1.4 infections per 1,000 resident-days. ${ }^{115}$ Infection of pressure ulcers is diagnosed primarily by clinical symptoms and signs. These local findings may range from nonhealing to overt presence of surrounding erythema, warmth, tenderness, and purulent discharge to presence of necrotic tissue and even crepitus. ${ }^{115-117}$ Signs of systemic inflammation, such as fever and leukocytosis, may be absent. Suggested-although unvalidated-criteria for diagnosis of infected pressure ulcer include presence of purulent discharge plus $\geq 4$ of the following characteristics: fever (temperature, $\geq 38^{\circ} \mathrm{C}$ ), worsening mental or functional status, warmth, redness, swelling, localized tenderness/pain, or serous drainage.

The surfaces of pressure ulcers are always colonized with bacteria; thus, cultures of specimens obtained from superficial swabs cannot differentiate between colonization and infection. The utility of fine-needle aspiration and deeptissue biopsy has been debated. Irrigation with saline and massage of the area followed by needle aspiration have been found to be very sensitive and specific in some studies; however, aspirates of clinically uninfected ulcers yield bacteria in $30 \%$ of instances. Correlations between swabs, aspiration, and deep-tissue biopsy specimen culture results have been poor. In general, deeper specimens are 
preferred for culture; however, positive culture results must be interpreted in conjunction with clinical and laboratory evidence that infection is present. Although a positive probe-to-bone test result has been shown to be predictive of osteomyelitis in patients with diabetes mellitus and lowerextremity ulcers, in pressure ulcers, the presence of exposed bone and of positive swab culture results is not diagnostic of osteomyelitis. Unfortunately, confirmation of osteomyelitis in pressure ulcers with exposed bone using histopathology, the gold standard for the diagnosis, yields positive results in only $<20 \%$ of cases, perhaps because of sampling error. Imaging may also provide supporting evidence that osteomyelitis is present; MRI is the most sensitive $(98 \%)$ and specific $(89 \%)$ diagnostic method. ${ }^{115-117}$

Most pressure ulcer infections are polymicrobial; aerobic gram-negative bacilli (e.g., E. coli, Proteus species, and Pseudomonas species), gram-positive cocci (e.g., streptococci and staphylococci), and anaerobic flora (e.g., bacteroides, peptostreptococci, and Clostridium perfringens) are found most commonly. Although blood cultures are not generally recommended for evaluation in nursing home-acquired infection, the presence of polymicrobial infection may provide supporting evidence that an infected pressure ulcer is the source. ${ }^{115-117}$ Most evaluations for acute osteomyelitis should be done in the acute care setting.

Conjunctivitis. Conjunctivitis is another common SSTI that occurs in $0.3 \%$ to $3.4 \%$ of LTCF residents or at a rate of $0.1-1.0$ cases per 1,000 resident-days. ${ }^{118}$ Conjunctivitis is primarily defined as the presence of purulent exudate or new or worsening redness in 1 or both eyes for at least $24 \mathrm{~h}$; allergy and trauma should be excluded. Ideally, treatment should be based on Gram stain results, culture results, and antibiotic susceptibilities of purulent discharge specimens obtained from the conjunctival sac. A cause may be established in $<40 \%$ of cases; most are due to $S$. aureus, Moraxella catarrhalis, Haemophilus species, epidemic strains of $S$. pyogenes, and, during outbreaks, adenovirus infection. Thus, therapy is often empirical, and close follow-up should be conducted for treatment failure.

Mucocutaneous Fungal Infection. SSTI may also result from the overgrowth of endogenous resident fungi in moist macerated skin and in association with use of antimicrobials and corticosteroids; infection with Candida species - typically Candida albicans - and dermatophytes may result. In one study, $84 \%$ of LTCF residents were colonized with yeast. ${ }^{119}$ Mucocutaneuous candidiasis may present as thrush, denture stomatitis, chelitis, paronychia, and intertrigo. Dermatophyte infection may manifest as tinea corporis, tinea pedis, tinea cruris, and tinea ungium (onychomycosis). Microscopic examination of scrapings following digestion with $10 \%$ potassium hydroxide can confirm the presence of Candida species or dermatophytes. ${ }^{120}$ If candidal infection fails to respond to empirical treatment, cultures and speciation of yeast should be performed. Azole-resistant Candida glabrata has been isolated with greater frequency from older adults with systemic fungal infection than from young adults, ${ }^{121}$ but there are no data for cutaneous disease.

Mucocutaneous Viral Infection. Reactivation of latent viral infection occurs with increasing age and waning immunity; 10,500-16,500 cases of herpes zoster occur in
LTCF residents each year. ${ }^{114}$ Herpes simplex virus infections typically present as vesicles or ulcerations involving nasolabial, genital, or rectal skin or mucosa. Reactivation of zoster presents as a painful vesicular rash typically in a dermatomal distribution. Presence of giant cells on Tzanck smear is diagnostic for herpes virus infection, and speciation between simplex and zoster can be confirmed by obtaining vesicle fluid specimens for immunofluorescence antigen testing, culture, or PCR. Differentiation between the two viral infections is important because of infection control issues and because of the increased doses of antivirals required for treatment of herpes zoster. ${ }^{14,122}$ The role of zoster vaccine in LTCF residents is undefined. ${ }^{123}$

Ectoparasitic Infection. Scabies (Sarcoptes scabiei) and lice (Pediculus humanus capitus, P. humanus corporis, and Phthirus pubis) are acquired by LTCF residents from other infected persons or contaminated fomites. ${ }^{124,125}$ The clinical presentation of scabies infection in nursing home patients can be atypical. Burrows, inflammatory changes in intertrigenous areas, and pruritis may be absent. Debilitated patients may present only with hyperkeratosis, papules, or vesicles. ${ }^{126}$ Diagnosis of scabies is often made when the typical rash occurs in healthcare workers or visitors. ${ }^{14,127}$ Debilitated older adults are often heavily infested with scabies mites. Scabies outbreaks are usually suspected by the occurrence of $\geq 1$ unexplained rash in residents. ${ }^{127}$ Although it may be necessary to make the diagnosis on the basis of clinical findings alone, an incorrect diagnosis can often lead to pseudo-outbreaks, with widespread "psychogenic" scabies (itching but no skin lesions), especially among staff or family members. Therefore, once scabies is suspected, an etiologic diagnosis should be attempted in several residents or staff. Skin should be scraped six or seven times with a scalpel, and examination of the scrapings under immersion oil by low-power microscopy readily detects mites, ova, and feces. ${ }^{125,126}$ Lice are typically found at the base of hair follicles (nits), in the scalp (head lice), or in the seams of clothing (body lice).

\section{Evaluation of GI Infection Recommendations}

28. In the absence of an outbreak of GI illness, residents with symptoms of gastroenteritis consistent with small bowel infection and a stable clinical status should be evaluated before 7 days for volume assessment, but no laboratory evaluation is required unless the resident is severely ill or symptoms persist beyond 7 days. In such cases, presence of Giardia species and other protozoa should be examined in stool specimens (B-III).

29. If the resident exhibits symptoms of colitis (e.g., severe fever, abdominal cramps, and/or diarrhea, with or without blood and/or WBCs in the stool), initial evaluation for C. difficile should be performed, especially if the patient has received antibiotics within the previous 30 days. Submit a single diarrheal stool specimen to the laboratory for a $C$. difficile toxin assay. If diarrhea persists and if the assay result is negative, submit 1 or 2 additional stool specimens for the toxin assay (A-II).

30. In a patient with symptoms of colitis but no history of antibiotic use within the previous 30 days and/or a negative $C$. difficile evaluation result, one should submit a 
stool sample for culture for isolation of the most frequent invasive enteropathogens (i.e., C. jejuni, Salmonella and Shigella species, and E. coli O157:H7) (A-II).

31. Local public health authorities should be consulted if rates of gastroenteritis or colitis exceed baseline thresholds in the facility (if these thresholds are known), if $\geq 2$ cases occur at the same time in the same unit, or if a reportable pathogen is isolated (B-III).

32. Intra-abdominal infections and abscesses can occur in LTCF residents as a consequence of GI pathology. These complications are relatively uncommon but are associated with substantial morbidity and mortality; evaluation and treatment of possible abscesses should be performed in an acute care setting (B-III).

\section{Evidence Summary}

Gastroenteritis and Diarrhea. Gastroenteritis and diarrhea are the most commonly encountered GI infections in LTCF residents. Diarrhea may be attributable to increased susceptibility or exposure to pathogens. Increased achlorhydria and reduced intestinal motility with age may allow the organism to survive in the stomach with slowed egress from the GI tract. Many medications and underlying diseases affect gastric acidity and slow gut motility in aged persons. Enteric pathogens may be acquired from environmental sources, direct contact with infected residents and hands of personnel, and ingestion of contaminated food and water. Visits by children and animals have also been associated with outbreaks. Devices such as feeding tubes or thermometers may provide an efficient means to introduce pathogens directly into the GI tract. ${ }^{128,129}$

Although the exact incidence of infectious diarrhea in LTCF is not known, numerous outbreaks reported from individual facilities suggest that the problem is common. It has been estimated that one-third of nursing home residents will have an episode of diarrhea annually. More than onehalf of all diarrheal deaths involve adults aged $\geq 74$ years; one-third of these deaths occur in LTCF residents. ${ }^{128,129}$

Gastroenteritis and diarrhea can be caused by the organism itself or by the elaboration of toxins. Causes of diarrhea in the LTCF may be bacterial, viral, or, less commonly, parasitic. A commonly used case definition of diarrhea includes the presence of $\geq 3$ watery, loose, or unformed stools per day for $>48 \mathrm{~h}$. In general, GI infection can be classified by the organ involved. Infection of the small bowel or gastroenteritis is most commonly associated with mid abdominal pain and large-volume watery stools; blood and pus in stool are rare. Typical small bowel pathogens include viruses and the protozoa Giardia lamblia and Cryptosporidium and Cyclospora species. ${ }^{130,131}$

In contrast to upper GI tract disease, infection of the large bowel is associated with lower abdominal or rectal pain; mucosal ulcers, blood, and fecal leukocytes or stool lactoferrin may be present. Causes of large-bowel infections described in LTCFs include C. difficile, toxigenic enterohemorrhagic E. coli, Shigella species, Salmonella species, Campylobacter species, Yersinia species, and Entamoeba bistolytica. Campylobacter, Yersinia, and Salmonella species also cause disease in the terminal ileum. ${ }^{130,131}$
Infections of the Small Intestine/Gastroenteritis. Viruses account for the majority of outbreaks of gastroenteritis that typically occur in the winter time in association with vomiting, respiratory symptoms, and headaches. ${ }^{129}$ Viral causes, such as norovirus, calciviruses, adenoviruses, enteroviruses, and rotavirus infections, are common. Viral diarrheas resolve with supportive treatment. Diagnosis is generally not required unless there is a prolonged outbreak that does not resolve with appropriate isolation techniques. Most new laboratory methods rely on the detection of viral antigens in stool by RT-PCR or enzyme immunoassay. ${ }^{131}$

Norovirus, a particularly prevalent and highly contagious agent, deserves specific comment for several reasons. First, fatal cases of norovirus infection occur the majority of the time among LTCF residents. ${ }^{130}$ Second, very small numbers of virus particles are infectious and can be transmitted by direct contact, by fomites, or by aerosolization during vomiting. This mandates stringent infection control procedures. ${ }^{132}$ Third, as with C. difficile (see below), alcohol hand preparations may not completely inactivate the organism, and vigorous handwashing with soap, friction, and running water is still preferred. ${ }^{133}$

Enterotoxin-producing foodborne strains of Bacillus cereus, C. perfringens, and $S$. aureus have caused epidemics of nausea and vomiting in nursing homes. The diagnosis of infection is made solely on the basis of the abrupt onset of nausea, vomiting, abdominal cramps, and diarrhea within 1-72 $\mathrm{h}$ after ingestion of suspect foods in multiple patients. Fever and inflammatory signs are lacking, and the episodes resolve in 24-48 h with supportive care. ${ }^{129,134}$

The parasites G. lamblia and Cryptosporidium parvum have been identified less often in association with contaminated food and water and with child-care programs. ${ }^{129,135}$ Diagnosis of infection with these organisms by antigen detection is more sensitive than examination of stool specimens for trophozoites and for cysts. ${ }^{136,137}$ Standard examinations of stool specimens for ova and parasites do not include the acid-fast staining required to detect Cryptosporidium, Cyclospora, or Isospora species. ${ }^{138}$

C. difficile Infection. C. difficile is the most common readily identifiable cause of infectious diarrhea in LTCF residents. ${ }^{129,139,140}$ Most other diarrheal pathogens are identified only after an outbreak is suspected. Rates of asymptomatic C. difficile colonization in LTCFs approach $10 \%-$ $30 \%,{ }^{140}$ in part because of decreases in protective antibody to toxin A with increasing age. ${ }^{139}$ Rates of symptomatic infection appear to be highest in subacute and rehabilitative units, especially after recent admission from a hospital. ${ }^{140}$ Under the selective pressure of antibiotics, growth of toxin-producing C. difficile occurs, with resulting diarrhea. One-third of nursing home residents already colonized with $C$. difficile will acquire symptomatic $C$. difficile-associated diarrhea within 2 weeks after receiving antibiotic therapy, ${ }^{139}$ highlighting the need to avoid unnecessary antibiotic use in this cohort. Alcohol preparations used for hand sanitizing in hospitals and LTCFs do not inactivate the spores of C. difficile; thus, strict handwashing (which mechanically removes the spores) is recommended after caring for patients with $C$. difficile illness. Nosocomial transmission of $C$. difficile by personto-person contact is now well recognized in institutional settings such as LTCFs. Therefore, outbreaks of diarrhea in 
LTCFs should prompt consideration of C. difficile-associated diarrhea as the diagnosis. ${ }^{140,141}$

Clinical manifestations of $C$. difficile infection range from mild diarrhea to pseudomembranous colitis to toxic megacolon. Recent C. difficile-associated diarrhea strains are clearly associated with increased incidence and severity of disease in the older adult, leading to increased rates of hospitalization, intensive care, surgical intervention, and death. ${ }^{141}$

The diagnosis of C. difficile should be strongly considered if the patient has received antibiotics or chemotherapy in the previous 4-6 weeks and for any older patient with severe leukocytosis $\left(>30,000\right.$ cells $\left./ \mathrm{mm}^{3}\right)$, even in the absence of abdominal pain, diarrhea, or recent antibiotic use. An EIA positive for toxins $\mathrm{A}$ or $\mathrm{B}$ in diarrheal stool specimens is diagnostic. Toxin assays are $60 \%-90 \%$ sensitive and $75 \%-$ $100 \%$ specific for detection of the organism, particularly if multiple specimens are tested. Stool cultures are not performed for patients without diarrhea, because C. difficile is part of normal GI flora. Sigmoidoscopy is less useful than assays for detection of toxin in stool specimens, because not all cases of C. difficile infection have pseudomembranes, and isolated right-side disease can be missed. ${ }^{139}$ Patients with signs of ileus or peritonitis should be transferred to a hospital for urgent imaging by CT and monitoring, if appropriate.

E. coli 0157:H7 and other Shiga toxin-producing enterohemorrhagic strains have been associated with foodborne outbreaks of bloody diarrhea without fever and hemolytic uremic syndrome. ${ }^{142}$ Diarrhea due to toxigenic strains of $E$. coli is diagnosed primarily with an assay of Shiga toxin or the presence of colorless colonies on Sorbitol-MacConkey agar cultures of stool specimens. ${ }^{128}$

Diarrhea due to invasive pathogens, such as Salmonella, Shigella, and Campylobacter species, have been associated with fever and prominent inflammatory signs, in addition to bloody stool, and are readily diagnosed by stool culture. ${ }^{129}$ Rarely, parasites such as Entamoeba histolytica have been identified as a cause of bloody diarrhea in this setting. ${ }^{129}$

Intra-Abdominal Infection and Abscesses. Complications of biliary tract and GI disease, such as appendiceal, hepatic, and diverticular abscesses, are uncommon but should be considered in febrile, older LTCF residents. The manifestations of these infections in this population are atypical, with a resulting delay in treatment and increased morbidity and mortality. Fever and focal findings on physical examination may be lacking, leading to perforation, abscess formation, and death. ${ }^{143}$

Compared with young adults, rates of diverticulitis and cholecystitis increase several-fold among older persons. ${ }^{143,144}$ Leading causes of intra-abdominal infections in older adults include appendicitis $(28 \%)$, diverticulitis $(28 \%)$, cholecystitis $(12 \%)$, cholangitis $(12 \%)$, and intra-abdominal abscess (9\%). ${ }^{143}$ Appendicitis is less common with aging but accounts for $15 \%$ of surgical emergencies among persons in this age group. ${ }^{144}$ Intra-abdominal abscess is also a leading diagnosis in older adults with fever of unknown origin. Evaluation for these infections should be considered to be a medical emergency that requires admission to an acute care facility.
VII. HOW SHOULD A SUSPECTED OUTBREAK OF A SPECIFIC INFECTIOUS DISEASE BE INVESTIGATED IN LTCFS?

\section{Recommendation}

33. During a possible outbreak of infection, testing of residents, regardless of advanced directive status, may be warranted for diagnostic and infection-control purposes for the protection of other residents and staff (B-III).

\section{Evidence Summary}

Although a broad description of outbreak investigation is beyond the scope of these guidelines, LTCFs commonly experience outbreaks of disease above endemic levels (i.e., epidemics). The role of the LTCF physician is to recognize an outbreak; to take immediate action regarding isolation, if required; and to notify the medical director and infectioncontrol practitioner or appropriate authorities (e.g., local public health department or the Centers for Disease Control and Prevention) for further assistance, if needed. ${ }^{145,146} \mathrm{Im}$ portantly, testing of LTCF residents, even those with advanced directives prohibiting such measures in their own care, may be done when the goal is to benefit the community of the LTCF. ${ }^{54}$ To facilitate early recognition of an outbreak, facilities should monitor their baseline infection rates using standard definitions.

The following initial steps should be initiated in recognizing an outbreak:

- Confirm the diagnosis of disease in the index patient.

- Decide and define key variables to study (before chart review) and involve a multidisciplinary team in planning the study.

- Derive a uniform case definition to be used in chart review and patient evaluation.

- With use of the case definition, perform a chart review and prospectively observe newly suspected cases.

- Plot an epidemic curve (number of cases over time) that includes a sufficient pre-epidemic period to establish that an outbreak truly exists.

- Determine whether the outbreak is a "pseudo-outbreak" (presence of positive laboratory results in the absence of clinical disease) that is now recognized because of a change in surveillance, laboratory and/or specimen collection methods, or altered procedures rather than a true increase in the number of cases.

- Review the relevant literature.

- Inform appropriate administrative personnel (director of nursing or department heads) of isolation procedures, if required.

- Seek assistance from local epidemiology personnel in the health department, the Centers for Disease Control and Prevention, or a hospital.

\section{PERFORMANCE MEASURES}

1. In LTCF residents suspected of having an infection, the temperature, pulse, blood pressure, and respiratory rate should be obtained by nursing home/facility personnel within $30 \mathrm{~min}$. 
2. In LTCF residents suspected of having an infection and in whom no prior advance directive prohibits further evaluation, a CBC count, including peripheral WBC count and differential cell counts, should be performed within 12-24 h (or sooner if the patient is seriously ill), consistent with local standards of practice.

\section{ACKNOWLEDGMENTS}

The Expert Panel wishes to express its gratitude to Jennifer Padberg for outstanding assistance throughout the review process and to Drs. Robert A. Bonomo, Keith S. Kaye, Lona Mody, and Robert J. Schreiber for their thoughtful review of earlier drafts of the guideline.

Financial support. Support for this guideline was provided by the Infectious Diseases Society of America.

Potential conflict of interest. K.P.H. has received research grants from Cubist Pharmaceuticals, Atlantic Philanthropies, Optimer, Viropharma, John A. Hartford Foundation, and Astellas Pharma; has served on the advisory board of Merck \& Co and on the Board of Directors of the American Board of Internal Medicine; and served on the speakers' bureaus of Merck \& Co. andWyeth. S.G. serves as a consultant for GlaxoSmithKline, The Wellcome Trust, Merck \& Co., Wyeth, and Sanofi-Aventis and is contracted through the Quality Partner of Rhode Island as the Clinical Director of Long Term Care Quality Improvement Organization Support Center. T.T.Y. is editor in chief of the Journal of the American Geriatrics Society. All other authors: no conflicts.

\section{REFERENCES}

1. Field MJ, Lohr KN, eds. Institute of Medicine Committee to Advise the Public Health Service on Clinical Practice Guidelines, Clinical Practice Guidelines: Directions for a New Program. Washington, DC: National Academy Press, 1990 .

2. Canadian Task Force on the Periodic Health Examination. The periodic health examination. Can Med Assoc J 1979;121:1193-1254.

3. Bentley DW, Bradley S, High K, Schoenbaum S, Taler G, Yoshikawa TT. Practice guideline for evaluation of fever and infection in longterm care facilities. Clin Infect Dis 2000;31:640-653.

4. Kinsella K, Velkoff VA. An Aging World: International Population Reports (Series P95/01-1). Washington, DC: US Government Printing Office, 2001.

5. High KP, Bradley S, Loeb M, Palmer R, Quagliarello V, Yoshikawa T. A new paradigm for clinical investigation of infectious syndromes in older adults: assessment of functional status as a risk factor and outcome measure. Clin Infect Dis 2005;40:114-122.

6. Centers for Diseases Control and Prevention. Trends in aging-United States and worldwide. MMWR Morb Mortal Wkly Rep 2003;52:101-104, 6.

7. Yoshikawa TT, Ouslander JG. Infection Management for Geriatrics in Long Term Care Facilities. New York: Informa Healthcare USA, 2007.

8. Centers for Diseases Control and Prevention. Nursing home facilities, 2006. Available at http://www.cdc.gov/nchs/data/nnhsd/nursing homefacilities 2006.pdf\#01 Accessed July 17, 2007.

9. Quagliarello V, Ginter S, Han L, Van Ness P, Allore H, Tinetti M. Modifiable risk factors for nursing home-acquired pneumonia. Clin Infect Dis 2005; 40:1-6

10. Khanna KV, Markham RB. A perspective on cellular immunity in the elderly. Clin Infect Dis 1999;28:710-713.

11. Loeb MB. Community-acquired pneumonia in older people: the need for a broader perspective. J Am Geriatr Soc 2003;51:539-543.

12. Burns EA, Goodwin JS. Immunodeficiency of aging. Drugs Aging 1997;11: 374-397.

13. van Duin D, Mohanty S, Thomas V et al. Age-associated defect in human TLR-1/2 function. J Immunol 2007;178:970-975.

14. van Duin D, Allore HG, Mohanty S et al. Prevaccine determination of the expression of costimulatory B7 molecules in activated monocytes predicts influenza vaccine responses in young and older adults. J Infect Dis 2007;195:1590-1597.

15. High K. Immunizations in older adults. Clin Geriatr Med 2007;23:669-685, viii-ix.

16. Loeb MB, Craven S, McGeer AJ et al. Risk factors for resistance to antimicrobial agents among nursing home residents. Am J Epidemiol 2003; 157:40-47.

17. Nicolle LE. Urinary tract infection in long-term-care facility residents. Clin Infect Dis 2000;31:757-761.

18. Medina-Walpole AM, Katz PR. Nursing home-acquired pneumonia. J Am Geriatr Soc 1999;47:1005-1015.

19. Yamaya M, Yanai M, Ohrui T, Arai H, Sasaki H. Interventions to prevent pneumonia among older adults. J Am Geriatr Soc 2001;49:85-90.

20. Fried TR, Gillick MR, Lipsitz LA. Short-term functional outcomes of longterm care residents with pneumonia treated with and without hospital transfer. J Am Geriatr Soc 1997;45:302-306.

21. Joaquin AM. Evaluation of infections in long-term care facilities versus acute care hospitals. In: Yoshikawa TT, Ouslander JG, eds. Infection Management for Geriatrics in Long-Term Care Facilities. New York: Informa Healthcare USA, 2007, pp 21-29.

22. Evans JM, Chutka DS, Fleming KC, Tangalos EG, Vittone J, Heathman JH. Medical care of nursing home residents. Mayo Clin Proc 1995;70:694-702.

23. Ouslander JG, Osterweil D. Physician evaluation and management of nursing home residents. Ann Intern Med 1994;120:584-592.

24. Smith PW, Rusnak PG. SHEA Long-Term-Care Committee and APIC Guidelines Committee. Infection prevention and control in the longtermcare facility. Infect Control Hosp Epidemiol 1997;18:831-849.

25. McGeer A, Campbell B, Emori TG et al. Definitions of infection for surveillance in long-term care facilities. Am J Infect Control 1991;19:1-7.

26. Smith PW. Consensus conference on nosocomial infections in longterm care facilities. Am J Infect Control 1987;15:97-100.

27. Berman P, Hogan DB, Fox RA. The atypical presentation of infection in old age. Age Ageing 1987;16:201-207.

28. Marrie TJ, Durant H, Kwan C. Nursing home-acquired pneumonia: a casecontrol study. J Am Geriatr Soc 1986;34:697-702.

29. McAlpine CH, Martin BJ, Lennox IM, Roberts MA. Pyrexia in infection in the elderly. Age Ageing 1986;15:230-234.

30. Samiy AH. Clinical manifestations of disease in the elderly. Med Clin North Am 1983;67:333-344.

31. Brooks S, Warshaw G, Hasse L, Kues JR. The physician decision-making process in transferring nursing home patients to the hospital. Arch Intern Med 1994;154:902-908.

32. Mehr DR, Binder EF, Kruse RL, Zweig SC, Madsen RW, D’Agostino RB. Clinical findings associated with radiographic pneumonia in nursing home residents. J Fam Pract 2001;50:931-937.

33. Castle SC, Norman DC, Yeh M, Miller D, Yoshikawa TT. Fever response in elderly nursing home residents: are the older truly colder? J Am Geriatr Soc 1991;39:853-857.

34. Castle SC, Yeh M, Toledo S, Yoshikawa TT, Norman DC. Lowering the temperature criterion improves detection of infections in nursing home residents. Aging Immunol Infect Dis 1993;4:67-76.

35. Norman DC, Yoshikawa TT. Fever in the elderly. Infect Dis Clin North Am 1996;10:93-99.

36. Darowski A, Najim Z, Weinberg J, Guz A. The febrile response to mild infections in elderly hospital inpatients. Age Ageing 1991;20:193-198.

37. Downton JH, Andrews K, Puxty JA. "Silent" pyrexia in the elderly. Age Ageing 1987;16:41-44.

38. Castle SC, Toledo SD, Daskal SL, Norman DC. The equivalency of infrared tympanic membrane thermometry with standard thermometry in nursing home residents. J Am Geriatr Soc 1992;40:1212-1216.

39. Ouslander JG. Medical care in the nursing home. JAMA 1989;262:25822590.

40. Kane RL, Garrard J, Skay CL et al. Effects of a geriatric nurse practitioner on process and outcome of nursing home care. Am J Public Health 1989;79: 1271-1277.

41. Jackson MM, Schafer K. Identifying clues to infections in nursing home residents: the role of the nurses' aide. J Gerontol Nurs 1993;19:33-42.

42. Garrard J, Kane RL, Radosevich DM et al. Impact of geriatric nurse practitioners on nursing-home residents' functional status, satisfaction, and discharge outcomes. Med Care 1990;28:271-283.

43. Rudman D, Hontanosas A, Cohen Z, Mattson DE. Clinical correlates of bacteremia in a Veterans Administration extended care facility. J Am Geriatr Soc 1988;36:726-732.

44. Yoshikawa TT, Norman DC. Approach to fever and infection in the nursing home. J Am Geriatr Soc 1996;44:74-82.

45. Zimmer JG, Bentley DW, Valenti WM, Watson NM. Systemic antibiotic use in nursing homes: a quality assessment. J Am Geriatr Soc 1986;34:703-710. 
46. McFadden JP, Price RC, Eastwood HD, Briggs RS. Raised respiratory rate in elderly patients: a valuable physical sign. Br Med J (Clin Res Ed) 1982; 284:626-627.

47. Sonnenblick M, Algur N. Hypernatremia in the acutely ill elderly patients: role of impaired arginine-vasopressin secretion. Miner Electrolyte Metab 1993;19:32-35.

48. Kirkland J, Lye M, Goddard F, Vargas E, Davies I. Plasma arginine vasopressin in arginine-vasopressin secretion. Miner Electrolyte Metab 1993; 19:32-35.

49. Weinberg AD, Pals JK, Levesque PG, Beal LF, Cunningham TJ, Minaker KL. Dehydration and death during febrile episodes in the nursing home. J Am Geriatr Soc 1994;42:968-971.

50. Gross CR, Lindquist RD, Woolley AC, Granieri R, Allard K, Webster B. Clinical indicators of dehydration severity in elderly patients. J Emerg Med 1992;10:267-274.

51. Magaziner J, Tenney JH, DeForge B, Hebel JR, Muncie HL Jr, Warren JW. Prevalence and characteristics of nursing home-acquired infections in the aged. J Am Geriatr Soc 1991;39:1071-1078.

52. Warren JW, Palumbo FB, Fitterman L, Speedie SM. Incidence and characteristics of antibiotic use in aged nursing home patients. J Am Geriatr Soc 1991;39:963-972.

53. Brown NK, Thompson DJ. Nontreatment of fever in extended-care facilities. N Engl J Med 1979;300:1246-1250.

54. Mott PD, Barker WH. Treatment decisions for infections occurring in nursing home residents. J Am Geriatr Soc 1988;36:820-824.

55. Franson TR, Schicker JM, LeClair SM, Hoffmann RG, Duthie EH Jr. Documentation and evaluation of fevers in hospital-based and communitybased nursing homes. Infect Control Hosp Epidemiol 1988;9:447-450.

56. Longo DR, Young J, Mehr D, Lindbloom E, Salerno LD. Barriers to timely care of acute infections in nursing homes: a preliminary qualitative study. J Am Med Dir Assoc 2002;3:360-365.

57. American Medical Directors Association (AMDA). Clinical Practice Guideline: Acute Change of Condition in the Long-Term Care Setting. Columbia, MD: AMDA, 2003.

58. Hutt E, Kramer AM. Evidence-based guidelines for management of nursing home-acquired pneumonia. J Fam Pract 2002;51:709-716.

59. Nicolle LE, Bentley D, Garibaldi R, Neuhaus E, Smith P. Antimicrobial use in long-term-care facilities. Infect Control Hosp Epidemiol 1996;17:119-128.

60. Valenti WM, Trudell RG, Bentley DW. Factors predisposing to oropharyngeal colonization with gram-negative bacilli in the aged. N Engl J Med 1978;298:1108-1111.

61. Yoshikawa TT, Nicolle LE, Norman DC. Management of complicated urinary tract infection in older patients. J Am Geriatr Soc 1996;44:12351241.

62. Nicolle LE. Urinary tract infections in long-term care facilities. Infect Control Hosp Epidemiol 1993;14:220-225.

63. Warren JW, Tenney JH, Hoopes JM, Muncie HL, Anthony WC. A prospective microbiologic study of bacteriuria in patients with chronic indwelling urethral catheters. J Infect Dis 1982;146:719-723.

64. Yoshikawa TT, Norman DC. Diagnostic approach to infections. In: Yoshikawa TT, Norman DC, eds. Aging and Clinical Practice Infectious Diseases Diagnosis and Treatment. New York: Igaku-Shoin, 1987, pp 26-31.

65. Montgomery P, Semenchuk M, Nicolle LE. Antimicrobial use in nursing homes in Manitoba. J Geriatr Drug Ther 1995;9:55-74.

66. Wasserman M, Levinstein M, Keller E, Lee S, Yoshikawa TT. Utility of fever, white blood cells, and differential count in predicting bacterial infections in the elderly. J Am Geriatr Soc 1989;37:537-543.

67. Mellors JW, Horwitz RI, Harvey MR, Horwitz SM. A simple index to identify occult bacterial infection in adults with acute unexplained fever. Arch Intern Med 1987;147:666-671.

68. Gleckman R, Hibert D. Afebrile bacteremia: a phenomenon in geriatric patients. JAMA 1982;248:1478-1481.

69. Kruse RL, Mehr DR, Boles KE et al. Does hospitalization impact survival after lower respiratory infection in nursing home residents? Med Care 2004;42:860-870.

70. Mylotte JM, Tayara A, Goodnough S. Epidemiology of bloodstream infection in nursing home residents: evaluation in a large cohort from multiple homes. Clin Infect Dis 2002;35:1484-1490.

71. Boscia JA, Kobasa WD, Abrutyn E, Levison ME, Kaplan AM, Kaye D. Lack of association between bacteriuria and symptoms in the elderly. Am J Med 1986;81:979-982.

72. Nicolle LE, Bradley S, Colgan R, Rice JC, Schaeffer A, Hooton TM. Infectious Diseases Society of America guidelines for the diagnosis and treatment of asymptomatic bacteriuria in adults. Clin Infect Dis 2005;40: 643-654.

73. Nicolle LE, Bjornson J, Harding GK, MacDonell JA. Bacteriuria in elderly institutionalized men. N Engl J Med 1983;309:1420-1425.
74. Nicolle LE, Mayhew WJ, Bryan L. Prospective randomized comparison of therapy and no therapy for asymptomatic bacteriuria in institutionalized elderly women. Am J Med 1987;83:27-33.

75. Norman DC, Yamamura R, Yoshikawa TT. Pyuria: its predictive value of asymptomatic bacteriuria in ambulatory elderly men. J Urol 1986;135: 520-522.

76. Monane M, Gurwitz JH, Lipsitz LA, Glynn RJ, Choodnovskiy I, Avorn J. Epidemiologic and diagnostic aspects of bacteriuria: a longitudinal study in older women. J Am Geriatr Soc 1995;43:618-622.

77. Juthani-Mehta M, Tinetti M, Perrelli E, Towle V, Quagliarello V. Role of dipstick testing in the evaluation of urinary tract infection in nursing home residents. Infect Control Hosp Epidemiol 2007;28:889-891.

78. Juthani-Mehta M, Tinetti M, Perrelli E, Towle V, Van Ness PH, Quagliarello V. Diagnostic accuracy of criteria for urinary tract infection in a cohort of nursing home residents. J Am Geriatr Soc 2007;55:1072-1077.

79. Tambyah PA, Maki DG. Catheter-associated urinary tract infection is rarely symptomatic: a prospective study of 1,497 catheterized patients. Arch Intern Med 2000;160:678-682.

80. Raz R, Schiller D, Nicolle LE. Chronic indwelling catheter replacement before antimicrobial therapy for symptomatic urinary tract infection. J Urol 2000;164:1254-1258.

81. Ouslander JG, Greengold BA, Silverblatt FJ, Garcia JP. An accurate method to obtain urine for culture in men with external catheters. Arch Intern Med 1987;147:2868.

82. Nicolle LE, Strausbaugh LJ, Garibaldi RA. Infections and antibiotic resistance in nursing homes. Clin Microbiol Rev 1996;9:1-17.

83. Muder RR, Brennen C, Wagener MM, Goetz AM. Bacteremia in a 170 longterm-care facility: a five-year prospective study of 163 consecutive episodes. Clin Infect Dis 1992;14:647-654.

84. Setia U, Serventi I, Lorenz P. Bacteremia in a long-term care facility: spectrum and mortality. Arch Intern Med 1984;144:1633-1635.

85. Richardson JP. Bacteremia in the elderly. J Gen Intern Med 1993;8:89-92.

86. Pfitzenmeyer P, Decrey H, Auckenthaler R, Michel JP. Predicting bacteremia in older patients. J Am Geriatr Soc 1995;43:230-235.

87. Lee CC, Chen SY, Chang IJ, Chen SC, Wu SC. Comparison of clinical manifestations and outcome of community-acquired bloodstream infections among the oldest old, elderly, and adult patients. Medicine (Baltimore) 2007;86:138-144.

88. Chassagne P, Perol MB, Doucet J et al. Is presentation of bacteremia in the elderly the same as in younger patients? Am J Med 1996;100:65-70.

89. Fontanarosa PB, Kaeberlein FJ, Gerson LW, Thomson RB. Difficulty in predicting bacteremia in elderly emergency patients. Ann Emerg Med 1992;21:842-848.

90. Mylotte JM. Nursing home-acquired bloodstream infection. Infect Control Hosp Epidemiol 2005;26:833-837.

91. Arbo MD, Snydman DR. Influence of blood culture results on antibiotic choice in the treatment of bacteremia. Arch Intern Med 1994;154:26412645.

92. Fine MJ, Auble TE, Yealy DM et al. A prediction rule to identify low-risk patients with community-acquired pneumonia. N Engl J Med 1997;336:243250 .

93. Mylotte JM, Naughton B, Saludades C, Maszarovics Z. Validation and application of the pneumonia prognosis index to nursing home residents with pneumonia. J Am Geriatr Soc 1998;46:1538-1544.

94. Chan Carusone SB, Walter SD, Brazil K, Loeb MB. Pneumonia and lower respiratory infections in nursing home residents: predictors of hospitalization and mortality. J Am Geriatr Soc 2007;55:414-419.

95. Bartlett JG, Mundy LM. Community-acquired pneumonia. N Engl J Med 1995;333:1618-1624.

96. Kaye KS, Stalam M, Shershen WE, Kaye D. Utility of pulse oximetry in diagnosing pneumonia in nursing home residents. Am J Med Sci 2002; 324:237-242.

97. Medina-Walpole AM, McCormick WC. Provider practice patterns in nursing home-acquired pneumonia. J Am Geriatr Soc 1998;46:187-192.

98. Wipf JE, Lipsky BA, Hirschmann JV et al. Diagnosing pneumonia by physical examination: relevant or relic? Arch Intern Med 1999;159:1082-1087.

99. Geckler RW, Gremillion DH, McAllister CK, Ellenbogen C. Microscopic and bacteriological comparison of paired sputa and transtracheal aspirates. J Clin Microbiol 1977;6:396-399.

100. Bentley DW, Ha K, Mamot $\mathrm{K}$ et al. Pneumococcal vaccine in the institutionalized elderly: design of a nonrandomized trial and preliminary results. Rev Infect Dis 1981;3(Suppl):S71-81.

101. Gauerke C, Drinka P, Faulks JT, Krause P, Nest L. Sputum bacteriology in nursing home pneumonia: a retrospective study. J Am Med Dir Assoc 2001;2:285-288.

102. Mandell LA, Wunderink RG, Anzueto A et al. Infectious Diseases Society of America/American Thoracic Society consensus guidelines on the manage- 
ment of community-acquired pneumonia in adults. Clin Infect Dis 2007; 44(Suppl 2):S27-72.

103. Seenivasan MH, Yu VL, Muder RR. Legionnaires' disease in longterm care facilities: overview and proposed solutions. J Am Geriatr Soc 2005;53: $875-880$.

104. Bradley SF. Long-Term-Care Committee of the Society for Healthcare Epidemiology of America. Prevention of influenza in long-term-care facilities. Infect Control Hosp Epidemiol 1999;20:629-637.

105. Falsey AR, Hennessey PA, Formica MA, Cox C, Walsh EE. Respiratory syncytial virus infection in elderly and high-risk adults. N Engl J Med 2005; 352:1749-1759.

106. Neuzil KM, Maynard C, Griffin MR, Heagerty P. Winter respiratory viruses and health care use: a population-based study in the northwest United States. Clin Infect Dis 2003;37:201-207.

107. Thompson WW, Shay DK, Weintraub E et al. Mortality associated with influenza and respiratory syncytial virus in the United States. JAMA 2003;289:179-186.

108. Falsey AR, Walsh EE. Viral pneumonia in older adults. Clin Infect Dis 2006; 42:518-24.

109. Dumyati G. Influenza and other respiratory viruses. In: Yoshikawa TT, Ouslander JG, eds. Infection management for geriatrics in longterm care facilities. New York: Informa Healthcare USA, 2007, pp 191-214.

110. Cox NJ, Subbarao K. Influenza. Lancet 1999;354:1277-1282.

111. Church DL, Davies HD, Mitton C et al. Clinical and economic evaluation of rapid influenza a virus testing in nursing homes in Calgary, Canada. Clin Infect Dis 2002;34:790-795.

112. Nicolle LE. Infection control in long-term care facilities. Clin Infect Dis 2000;31:752-756.

113. Lertzman BH, Gaspari AA. Drug treatment of skin and soft tissue infections in elderly long-term care residents. Drugs Aging 1996;9:109-121.

114. Schmader K, Twersky J. Herpes zoster, cellulitis, and scabies. In: Yoshikawa TT, Ouslander JG, eds. Infection management for geriatrics in long-term care facilities. New York: Informa Healthcare USA, 2007, pp 277-296.

115. Livesley NJ, Chow AW. Infected pressure ulcers in elderly individuals. Clin Infect Dis 2002;35:1390-1396.

116. Smith PW, Black JM, Black SB. Infected pressure ulcers in the longterm- care facility. Infect Control Hosp Epidemiol 1999;20:358-361.

117. Reynolds SC, Chow A. Infected pressure ulcers. In: Yoshikawa TT, Ouslander JG, eds. Infection management for geriatrics in long-term care facilities. New York: Informa Healthcare USA, 2007, pp 251-276.

118. Boustcha E, Nicolle LE. Conjunctivitis in a long-term care facility. Infect Control Hosp Epidemiol 1995;16:210-216.

119. Hedderwick SA, Wan JY, Bradley SF, Sangeorzan JA, Terpenning MS, Kauffman CA. Risk factors for colonization with yeast species in a Veterans Affairs long-term care facility. J Am Geriatr Soc 1998;46:849-853.

120. Kauffman CA, Hedderwick SA. Fungal infections. In: Yoshikawa TT, Ouslander JG, eds. Infection management for geriatrics in long-term care facilities. New York: Informa Healthcare USA, 2007, pp 445-464.

121. Kauffman CA. Fungal infections in older adults. Clin Infect Dis 2001;33: 550-555.

122. Schmader K. Herpes zoster in older adults. Clin Infect Dis 2001;32:14811486.

123. Oxman MN, Levin MJ, Johnson GR et al. A vaccine to prevent herpes zoster and postherpetic neuralgia in older adults. N Engl J Med 2005;352:22712284 .

124. Heukelbach J, Feldmeier H. Scabies. Lancet 2006;367:1767-1774.

125. Chosidow O. Clinical practices: scabies. N Engl J Med 2006;354:17181727.
126. Wilson MM, Philpott CD, Breer WA. Atypical presentation of scabies among nursing home residents. J Gerontol A Biol Sci Med Sci 2001;56A:M424-427.

127. Degelau J. Scabies in long-term care facilities. Infect Control Hosp Epidemiol 1992;13:421-425.

128. Mishkin DS, Brandt LJ. CME article: management and treatment of infectious diarrhea in the elderly. Clin Geriatr Med 2003;11:44-53.

129. Strausbaugh LJ, Sukumar SR, Joseph CL. Infectious disease outbreaks in nursing homes: an unappreciated hazard for frail elderly persons. Clin Infect Dis 2003;36:870-876.

130. Acheson D, Nataro J. Digestive system infections. In: Engleberg NC, DiRita V, Dermody TS, eds. Schaechter's mechanisms of microbial disease. Philadelphia: Lippincott, Williams, \& Wilkins, 2007, pp 572-587.

131. Guerrant RL, Van Gilder T, Steiner TS et al. Practice guidelines for the management of infectious diarrhea. Clin Infect Dis 2001;32:331-351.

132. Wu HM, Fornek M, Schwab KJ et al. A norovirus outbreak at a longtermcare facility: the role of environmental surface contamination. Infect Control Hosp Epidemiol 2005;26:802-810.

133. Drinka PJ. Norovirus outbreaks in nursing homes. J Am Geriatr Soc 2005;53: 1839-1840.

134. Levine WC, Smart JF, Archer DL, Bean NH, Tauxe RV. Foodborne disease outbreaks in nursing homes, 1975 through 1987. JAMA 1991;266:21052109.

135. Neill MA, Rice SK, Ahmad NV, Flanigan TP. Cryptosporidiosis: an unrecognized cause of diarrhea in elderly hospitalized patients. Clin Infect Dis 1996;22:168-170.

136. Chen XM, Keithly JS, Paya CV, LaRusso NF. Cryptosporidiosis. N Engl J Med 2002;346:1723-1731.

137. Mank TG, Zaat JO. Diagnostic advantages and therapeutic options for giardiasis. Expert Opin Investig Drugs 2001;10:1513-1519.

138. Leav BA, Mackay M, Ward HD. Cryptosporidium species: new insights and old challenges. Clin Infect Dis 2003;36:903-908.

139. Simor AE, Bradley SF, Strausbaugh LJ, Crossley K, Nicolle LE. Clostridium difficile in long-term-care facilities for the elderly. Infect Control Hosp Epidemiol 2002;23:696-703.

140. Laffan AM, Bellantoni MF, Greenough WB 3rd, Zenilman JM. Burden of Clostridium difficile-associated diarrhea in a long-term care facility. J Am Geriatr Soc 2006;54:1068-1073.

141. Loo VG, Poirier L, Miller MA et al. A predominantly clonal multiinstitutional outbreak of Clostridium difficile-associated diarrhea with high morbidity and mortality. N Engl J Med 2005;353:24422449.

142. Reiss G, Kunz P, Koin D, Keeffe EB. Escherichia coli O157: H7 infection in nursing homes: review of literature and report of recent outbreak. J Am Geriatr Soc 2006;54:680-684.

143. Carson JG, Patterson RW, Wilson SE. Medical and surgical treatment of intra-abdominal infections. In: Yoshikawa TT, Rajagopalan S, eds. Antibiotic therapy for geriatric patients. New York: Taylor \& Francis, 2006, pp 453471.

144. Campbell BS, Wilson SE. Intraabdominal infections. In: Yoshikawa TT, Ouslander JG, eds. Infection management for geriatrics in longterm care facilities. New York: Informa Healthcare USA, 2007, pp 91-98.

145. Beck-Sague C, Sot-Caceres V, Jarvis WR. Outbreak investigations. In: Lautenbach E, Woeltje K, eds. The Society for Healthcare Epidemiology of America practical handbook for healthcare epidemiologists. Thorofare, NJ: Slack, 2004, pp 99-110.

146. Smith PW, Bennett G, Bradley S et al. SHEA/APIC guideline: infection prevention and control in the long-term care facility, July 2008. Infect Control Hosp Epidemiol 2008;29:785-814. 